Inhibition of Islet Amyloid Polypeptide Aggregation and Associated Cytotoxicity by Non-steroidal Anti-Inflammatory Drugs

\begin{tabular}{|r|l|}
\hline Journal: & Canadian Journal of Physiology and Pharmacology \\
\hline Manuscript ID & cjpp-2015-0117.R2 \\
\hline Manuscript Type: & Article \\
\hline Date Submitted by the Author: & 26-May-2015 \\
\hline Complete List of Authors: & $\begin{array}{l}\text { Fortin, Jessica; University of Montreal, Faculté de médecine vétérinaire, } \\
\text { Département de pathologie et microbiologie } \\
\text { Benoit-Biancamano, Marie-Odile; Université de montreal, }\end{array}$ \\
\hline Keyword: & Amyloid, NSAID, anti-amyloidogenic activity, IAPP, fibrils \\
\hline \multicolumn{2}{|l}{} \\
\hline
\end{tabular}

SCHOLARONE

Manuscripts 


\section{Inhibition of Islet Amyloid Polypeptide Aggregation and Associated Cytotoxicity by Non-steroidal Anti-Inflammatory Drugs}

Jessica S. Fortin $^{1}$ and Marie-Odile Benoit-Biancamano ${ }^{1}$

${ }^{1}$ Département de Pathologie et de Microbiologie, Faculté de Médecine Vétérinaire, Université de Montréal, Saint-Hyacinthe, QC, Canada, J2S 2M2.

Corresponding author: Marie-Odile Benoit-Biancamano, Faculté de médecine vétérinaire, Département de pathologie et microbiologie, Université de Montréal, 3200 Sicotte, St-Hyacinthe, QC, J2S 2M2. Tel.: 450-773-8521 ext. 8539, Fax: 450-778-8116.

E-mail: marie-odile.benoit-biancamano@umontreal.ca (MOBB), jessica.fortin.2@umontreal.ca(JF). 


\title{
Inhibition of Islet Amyloid Polypeptide Aggregation and Associated Cytotoxicity by Non-steroidal Anti-Inflammatory Drugs
}

Jessica S. Fortin and Marie-Odile Benoit-Biancamano

\begin{abstract}
Non-steroidal anti-inflammatory drugs (NSAIDs) constitute an important pharmacotherapeutic class which, over the past decade, have expanded in application to a panoply of medical conditions. They have been tested for neurodegenerative diseases such as Alzheimer's to reduce the inflammation and also in the attempt to abrogate amyloid deposition. However, the use of NSAID as aggregation inhibitors has not been extensively studied in pancreatic amyloid deposition. Pancreatic amyloidosis involves the misfolding of islet amyloid polypeptide (IAPP) and contributes to the progression of type 2 diabetes in the human and feline. To ascertain their anti-amyloidogenic activity, several NSAIDs were tested using fluorometric ThT assays, circular dichroism, photo-induced cross-linking assays and cell culture. Celecoxib, diclofenac, indomethacin, meloxicam, niflumic acid, nimesulide, phenylbutazone, piroxicam, sulindac, tenoxicam reduced fibrillization at a molar ratio of 1:10. The circular dichroism spectra of diclofenac, piroxicam and sulindac showed characteristic spectral signatures found in predominantly $\alpha$-helical structures. The oligomerization of hIAPP was abrogated with diclofenac and sulindac at a molar ratio of 1:5. The cytotoxic effects of pre-incubated hIAPP on cultured INS-1 cells were noticeably reduced in the presence of diclofenac, meloxicam, phenylbutazone, sulindac and tenoxicam at a molar ratio of 1:10. Our results demonstrate that NSAIDs can provide chemistry scaffolds to generate new promissing antiamyloidogenic agents that can be used alone or as a coadjuvant therapy.
\end{abstract}


Key words: Amyloid, anti-amyloidogenic activity, degenerative disease, fibrils, IAPP, NSAID, protein misfolding, type 2 diabetes.

\section{Introduction}

Diseases involving abnormal folding of proteins and conversion to an insoluble state are numerous in human and veterinary medicine, with more than thirty diseases related specifically to amyloid formation, including Alzheimer's disease (AD), type 2 diabetes, Parkinson's disease, prion disease and familial amyloidosis (Sipe et al. 2014). Protein misfolding, in amyloidosis, is characterized by a monomeric protein which is assembled into $\beta$-sheet insoluble fibrils (Hard and Lendel 2012). These amyloid deposits damage the cell membrane, inducing reactive oxygen species and apoptosis (Abedini and Schmidt 2013; Jayasinghe and Langen 2007; Jelinek and Sheynis 2010). Amyloid deposits may be localized in a tissue or generalized in different organs depending on the origin of the constitutive protein (Hard and Lendel 2012; Sipe et al. 2014). Amyloidogenic proteins do not share a common amino acid sequence nor a similar secondary or tertiary conformation in the native state. However, all types of amyloid have in common the formation of fibrils, with unique physicochemical characteristics as follows: a diameter of $5-15 \mathrm{~nm}$, a cross- $\beta$ sheet quaternary structure, a poor solubility in acidic or basic environments, and a resistance to extreme temperatures (Cheng et al. 2013; Hard and Lendel 2012). Several amyloidogenic proteins, such as TTR, are rich in beta-sheet in their soluble native conformation. 
In the past few decades, extensive effort has been expended to understand the pathophysiology of amyloidosis related to degenerative diseases such as Alzheimer's disease (AD) and type 2 diabetes, potentially leading to new therapeutic strategies. Although the actual details of many of the steps are unclear, the assembly of amyloidogenic proteins into a fibrillar structure occurs in stepwise fashion. An apparent early step in the aggregation is the formation of a set of conformationally diverse oligomers (Brender et al. 2015; Buchanan et al. 2014; Mishra et al. 2009), present at low abundance (Suzuki et al. 2012), with structures different from either the native largely unstructured peptide (Reddy et al. 2010; Williamson and Miranker 2007; Yonemoto et al. 2008) or the mature amyloid fiber (Luca et al. 2007). Subsequently, the oligomers assemble into a mature fibril. At this point, the proteins have a $\beta$-sheet secondary structure (Luca et al. 2007; Westermark et al. 2011). In parallel, these oligomers act as a seed, thereby initiating the aggregation and propagation of fibrils (Westermark et al. 2011). Although several factors can influence the fibrillar aggregation, the precise mechanisms are not clearly identified. More research on the mechanisms underlying the fibrillar aggregation will be crucial in the discovery of new antiamyloidogenic agents. The development of an inhibitor is also challenging considering that it doesn't require to stabilize solely the native protein or the oligomers (Cheng et al. 2013; Hard and Lendel 2012; Porat et al. 2006). The most common approach in pharmaceutical discovery research against amyloidogenic proteins involves exploring inhibitors of fibrillar deposition (Cheng et al. 2013; Hard and Lendel 2012; Porat et al. 2006). Perhaps, the best way to inhibit amyloid formation is by stabilizing the native conformation by small molecules, i.e. Tafamidis and TTR. 
Substantive clinical research has focused on inflammation as a critical component in amyloidogenic diseases. The use of NSAIDs has been demonstrated to delay the onset of Alzheimer's disease (AD) (Dong et al. 2014; Lim et al. 2000; Yan et al. 2003). Whether selective COX-2 inhibitors have clinical benefits with direct effects on brain amyloid deposition remain to be elucidated. Interestingly, the diarylamine classes, including diclofenac, were effective in inhibiting fibril formation related to other diseases, such as familial amyloid cardiomyopathy (FAC) and familial amyloid polyneuropathy (FAP), that involve transthyretin (TTR) amyloid formation (Oza et al. 2002). Others studies were performed in the attempt to inhibit amyloid formation related to type 2 diabetes. Amyloid deposits localized in the islets involve the misfolding of islet amyloid polypeptide (IAPP) and contribute to the progression of type 2 diabetes in human and diabetes mellitus in adult cats (Hoppener et al. 2002; Jaikaran and Clark 2001; O'Brien et al. 1993; Westermark et al. 2011). The effect of aspirin and ketoprofen were examined in pancreatic amyloidosis (Tu et al. 2014). However, these drugs failed to inhibit amyloid formation or to disaggregate preformed fibrils (Tu et al. 2014).

The implication of NSAIDs as IAPP aggregation inhibitors has not been extensively explored and their clinical benefits remain to be elucidated. This study focusses on the investigation of NSAIDs in inhibiting amyloidosis related to type 2 diabetes, with a potential therapeutic target of hIAPP fibrils. We describe the inhibition activity of a number of commercially available NSAIDs on hIAPP fibrils formation. The information gained from this study will help further structure-activity relationship studies for designing new derivatives with improved potency. 


\section{Materials and Methods}

\section{Chemicals}

Aceclofenac, diclofenac, DMSO, Hexafluoroisopropanol (HFIP), ibuprofen, ketoprofen, meloxicam, naproxen, nimesulide, phenylbutazone, resveratrol, resazurin, silibinin, sulindac, tenoxicam and thioflavin-T (ThT) were obtained from Alfa Aesar (Ward Hill, MA). Celecoxib, etoricoxib, indometacin, ketorolac, flurbiprofen, niflumic acid, oxaprozin, piroxicam, rofecoxib and valdecoxib were purchased from SigmaAldrich (St. Louis, MO).

\section{Cell line and culture}

INS-1 (rat insulinoma) cells were purchased from AddexBio (San Diego, CA) and cultured in RPMI1640 medium supplemented with 10 mM HEPES, 2 mM L-glutamine, $1 \mathrm{X}$ sodium pyruvate, $50 \mu \mathrm{M}$ 2-mercaptoethanol, $100 \mathrm{U} / \mathrm{mL}$ streptomycin, $100 \mathrm{U} / \mathrm{mL}$ of penicillin $\mathrm{G}$ and $10 \%$ fetal bovine serum (Wisent Inc., St-Bruno, Qc, Canada). Cells were maintained in a moisture saturated atmosphere at $37^{\circ} \mathrm{C}$ under $5 \% \mathrm{CO}_{2}$.

\section{Peptide synthesis}

Synthetic hIAPP (1-37) was obtained from Peptidogen International Corp (Brossard, Qc, Canada). Peptides were prepared, as previously published, with a microwave peptide synthesizer, using 9-fluornylmethoxycarbonyl (Fmoc) chemistry, and Fmoc-protected pseudoproline dipeptide derivatives were incorporated to facilitate the synthesis (Cao et al. 2013). The peptides were purified by reverse-phase HPLC using a 
C18 preparative column. The identity of the pure products was confirmed by mass spectrometry using a Bruker MALDI-TOF MS. Analytical HPLC was used to check the purity of the peptides $(\geq 95 \%)$ before each experiment. The purified peptide was lyophilized.

\section{Sample preparation}

hIAPP stock solutions were prepared by dissolving the hIAPP peptide at $1 \mathrm{mM}$ in 100\% HFIP and incubating for at least $12 \mathrm{~h}$. For the ThT kinetics, circular dichroism spectrometry and photo-induced cross-linking based oligomerization assays, hIAPP peptide stock solutions were prepared by dissolving peptides at $1 \mathrm{mM}$ in $100 \%$ HFIP. For the cytotoxicity assays, the IAPP peptide stock solutions of $1 \mathrm{mM}$ were divided in aliquots to obtain the desired final concentration and were air-dried. Aliquots of the stock solutions were dried to remove organic solvents and suspended in $10 \mathrm{mM}$ PBS buffer ( $\mathrm{pH}$ 7.4) at the desired concentration. hIAPP was dissolved in DMSO and PBS. DMSO was used at a final concentration lower than $0.1 \%(\mathrm{v} / \mathrm{v})$ to avoid cell toxicity.

\section{Thioflavin T (ThT) fluorescence assay}

hIAPP peptide from the stock solution of $1 \mathrm{mM}$ were added to $10 \mathrm{mM}$ PBS buffer (pH 7.4) and transferred to a black 96-well microplate with transparent bottom (Corning Incorporated Costar ${ }^{\circledR}$ 3603). Each well contained a final volume of $150 \mu \mathrm{L}$ with a peptide final concentration of $10 \mu \mathrm{M}$. Experiments in the presence of hIAPP were initiated by adding a solution of ThT at a final concentration of $10 \mu \mathrm{M}$ ThT with different drug treatments. Final drug concentrations ranged from 25 to $100 \mu \mathrm{M}$. All drugs were 
dissolved in DMSO at a final concentration lower than $0.25 \%(\mathrm{v} / \mathrm{v})$. The vehicle DMSO was tested on hIAPP, without drug treatment, and did not change the kinetics.

The background signal consisted of $1 \%$ HFIP without peptide. Thioflavin Tbased fluorescence assays were used to detect the formation of amyloid. The fluorescence emission experiments were performed with the excitation and emission wavelengths set at 440 and $485 \mathrm{~nm}$, respectively, with a Synergy HT multi-mode microplate reader (BioTek, Winooski, VT). Measurements were taken with two different periods of agitation prior to plate reading. Agitation during incubation leads to shorter aggregation times due to the increased rate of nucleation due to the formation of new nuclei by the breakage of amyloid fibers during agitation (Padrick and Miranker 2002; Ruschak and Miranker 2007; Shvadchak et al. 2015). For measurements with long agitation, measurements were taken at room temperature every 2 min with 10 seconds shaking prior measurements over $6 \mathrm{~h}$. Short agitation measurements were obtained by shaking the plate prior measurement for $5 \mathrm{sec}$ to ensure proper mixing and subsequently measuring the fluorescence intensity every $10 \mathrm{~min}$. Samples were measured in three replicates and the experiments were repeated three times using different IAPP stock solutions. For each time point, arbitrary units of fluorescence were calculated from the mean values normalized against the maximum value in each completed assay. Arbitrarily, the maximum value $(100 \%)$ for the fluorescence intensity was established for hIAPP peptide. The lag time and the $\mathrm{T}_{50}$ were calculated as previously described (Zhang et al. 2011).

\section{Far-Ultraviolet (UV) circular discroism (CD)}


CD spectra of the secondary structure of hIAPP samples were recorded at $25^{\circ} \mathrm{C}$ under a constant flow of $\mathrm{N}_{2}$ using a JASCO-810 spectropolarimeter (Jasco, Easton, MD). Spectra were recorded over a wavelength range of 190-250 nm using a quartz cuvette of $1 \mathrm{~mm}$ path length and an instrument scanning speed of $100 \mathrm{~nm} / \mathrm{min}$, with a response time of $2 \mathrm{sec}$ and a bandwidth of $1 \mathrm{~nm}$. Samples were not agitated. All IAPP samples were dissolved to a final concentration of $15 \mu \mathrm{M}$ in $10 \mathrm{mM}$ PBS (pH 7.4) and 1\% HFIP, and where appropriate, the samples contained different drug treatments at a final concentration of $25 \mu \mathrm{M}$. Each result is given as the average scans taken of three measurements at room temperature. The data were converted to mean residue ellipticity $(\theta)$ and analyzed using the software CDPro as previously described (Sreerama and Woody 2004). All CD spectra were averaged, smoothed and baseline-corrected for signal contributions due to the buffer.

\section{Photo-induced cross-linking (PICUP) assay}

hIAPP was diluted in $10 \mathrm{mM}$ phosphate buffer $(\mathrm{pH}$ 7.4) to a final concentration of $250 \mu \mathrm{M}$ peptide and 1\% HFIP. The peptide solution was sonicated for $1 \mathrm{~min}$. Drugs were also freshly dissolved in DMSO and added to the peptide solution at a molar ratio of 1:5 (hIAPP:compound). The control consisted of samples that were photo-cross-linked using the PICUP method as described (Bitan and Teplow 2004). The reaction buffer consisted of $938 \mu \mathrm{M} \mathrm{Ru}$ (bpy), $18.8 \mathrm{mM}$ ammonium persulfate and $250 \mu \mathrm{M}$ hIAPP. Cross-linking was induced by irradiation, for $3 \mathrm{~s}$, of the mixture, at a final volume of $60 \mu \mathrm{L}$, with a 150 W incandescent lamp installed in a homemade dark-box. After irradiation, $25 \mu \mathrm{L}$ of Lammeli loading buffer was immediately added to the solution, followed by incubation at 
$37{ }^{\circ} \mathrm{C}$ for $15 \mathrm{~min}$. The cross-linked samples were separated on a $16 \%$ Tricine-urea gel and visualized by silver staining.

\section{Cell viability assay}

Cells were maintained in a $37^{\circ} \mathrm{C}, 5 \% \mathrm{CO}_{2}$ incubator, in exponential growth, for the duration of experimentation. For this assay, cells were seeded in 96-well microtiter plates at a density of $5 \times 10^{3}$ Ins- 1 cells per well for $24 \mathrm{~h}$. Drugs freshly solubilized in DMSO were diluted in culture medium and aliquots containing sequential dilution of drugs were added subsequently after stimulation with $2.5 \mu \mathrm{M}$ of hIAPP. hIAPP was dissolved and incubated in $10 \mathrm{mM}$ PBS ( $\left.\mathrm{pH} \mathrm{7.4,25}{ }^{\circ} \mathrm{C}\right) 24 \mathrm{~h}$ before addition to cells. Drugs were tested at 25 and $50 \mu \mathrm{M}$ and DMSO concentration was maintained at $0.1 \%$ to avoid growth inhibition. Negative control consisted of DMSO with no added drug. Plates were incubated for $24 \mathrm{~h}$ in the presence of drugs and hIAPP. Resazurin-based reduction assays were performed as previously described (Fortin et al. 2010). Briefly, Resazurin (25 $\mu \mathrm{g} / \mathrm{mL}$ ) was added to the culture medium of each well for $1 \mathrm{~h} 30$ at $37^{\circ} \mathrm{C}$. The cell viability was calculated from fluorescence (excitation, $530 \mathrm{~nm}$; emission, $590 \mathrm{~nm}$ ) measured with a Synergy HT multi-mode microplate reader (BioTek, Winooski, VT). The data from experiments conducted in triplicate were corrected for the background fluorescence of the medium and was expressed as the mean percentage of fluorescence obtained for control DMSO-treated cells. The growth inhibition percentage was calculated with reference to DMSO-treated cells for each drug concentrations. The results were obtained from at least three separated experiments. The cell viability assay was considered valid when the variability among data for a given set of conditions, within the 
same experiment, was less than $10 \%$ with respect to the mean value. All values represent means $\pm \operatorname{SEM}(\mathrm{n}=3)$.

\section{Statistical analysis}

All results in Table 2, Table 3 and Figure 4 were presented as mean \pm SD. For the cell viability assays, data were analyzed by the one-way analysis of variance with Dunnett's multiple comparison between IAPP and several drug treatments. Differences were considered statistically significant at $p<0.05$ and $p<0.001$.

\section{Results}

\section{NSAIDs are effective inhibitors of hIAPP aggregation}

Table 1 displays the classification and molecular structure of NSAIDs used in this study. The effects of NSAIDs on the kinetics of hIAPP fibrillization using thioflavin T (ThT) fluorescence assay were examined. ThT binds to the cross $\beta$-structure of amyloid fibrils, theoretically in the surface grooves generated by stacking parallel $\beta$-sheets (Buell et al. 2010). The self-quenching of the fluorescent dye is relieved by the conformational changes induced by amyloid binding, resulting in fluorescence enhancement (Buell et al. 2010). The expected sigmoidal time course is observed when hIAPP is incubated without drug treatments (Fig. 1) (Paulsson et al. 2011). In the absence of drugs, the time required to reach half of the total fluorescence signal $\left(\mathrm{T}_{50}\right)$ was $39.9 \pm 0.2 \mathrm{~min}$ for samples with longer agitation during measurement and 105,3 \pm 0.7 min for samples with shorter agitation during measurement. For both samples, diclofenac and phenylbutazone significantly increased the $\mathrm{T}_{50}$ at a molar ratio of 1:10 (10 $\mu \mathrm{M}$ of hIAPP:100 $\mu \mathrm{M}$ of drug) 
(Table 2 and Table 4). Positive controls (resveratrol, silibinin) (Cheng et al. 2012; Jiang et al. 2011) and NSAIDs treatments shown in Fig. 1 (celecoxib, diclofenac, indomethacin, meloxicam, niflumic acid, nimesulide, phenylbutazone, piroxicam, sulindac, tenoxicam) significantly reduced the fluorescence intensity at a molar ratio of 1:10. The curves in these graphs exhibit a different slope for the treated and untreated groups. The time during which no significant fibril formation occurs followed by a rapid growth phase (lag time) was shorter for meloxicam, nimesulide, piroxicam, sulindac, tenoxicam, resveratrol and silibinin in Table 4. Interestingly, diclofenac and phenylbutazone prolonged the lag time. NSAID treatments such as niflumic acid, nimesulide and sulindac maintained their efficacy in reducing the amyloidogenicity of hIAPP fibrils using a molar ration of 1:5 (10 $\mu \mathrm{M}$ of hIAPP:50 $\mu \mathrm{M}$ of drug). The ThT fluorescence of h-IAPP was reduced by the presence of $25 \mu \mathrm{M}$ and $50 \mu \mathrm{M}$ of meloxicam (Table 3). Other NSAIDs, such as COX-2 inhibitors, had no detectable effect on the kinetics of amyloid formation and the final fluorescence intensity.

\section{NSAIDs induce secondary structure changes of hIAPP}

Amyloid formation involves the oligomerization of hIAPP and the formation of mature linear fibrils by the oligomer self-assembly (Buchanan et al. 2013; Cao et al. 2013; Hard and Lendel 2012). The first and the last steps are characterized by the $\alpha$ helical structure and $\beta$-sheet structure, respectively (Buchanan et al. 2013; Cao et al. 2013; Hard and Lendel 2012). To monitor the effect of NSAIDs on hIAPP oligomerization and self-assembly into mature fibrils, the secondary structure was determined by Far-UV CD. Spectra were recorded using hIAPP at $15 \mu \mathrm{M}$ and drug 
treatments at $25 \mu \mathrm{M}$ (molar ratio of 1:1.67). The assay is limited by the spectral interference of aromatic compounds at higher concentration. Random coil structures were predominant for the untreated condition at an incubation time of time 0 and 15 minutes (data not shown). Spectra indicative of random coil structure are characterized by a single minimum around 200-205 $\mathrm{nm}$. A conformational transition to $\beta$-sheet occurred after an incubation time of 30 minutes (data not shown). After an incubation time of $1 \mathrm{~h}$, a major negative peak at $220 \mathrm{~nm}$ was observed, indicative of a predominant $\beta$-sheet secondary structure. The CD spectra recorded at an incubation time of $1 \mathrm{~h}$ were shown to compare the untreated and treated conditions (Fig. 2).

The CD spectra of niflumic acid, phenylbutazone, and nimesulide showed evidence of extensive $\beta$-sheet formation at the final time point, suggesting the decrease in ThT fluorescence intensity may be due to the displacement of the ThT dye (Suzuki et al. 2012) or to the formation of non-fibrillar but still $\beta$-sheet aggregates. The spectrum of IAPP in presence of diclofenac, piroxicam and, to a lesser extent, sulindac shows the two negative peaks at $208 \mathrm{~nm}$ and around $220-221 \mathrm{~nm}$ characteristic of the exciton splitting found in predominantly $\alpha$-helical structures. Silibinin, tenoxicam, and meloxicam showed a mixed $\beta$-sheet/random coil spectra at the final time-point, indicating a delayed transition or the formation of more disordered aggregates than the fibers produced in the absence of these inhibitors. Resveratrol showed a more complicated, less easily interpreted spectrum.

\section{NSAIDs abrogate the oligomerization of hIAPP}


Soluble oligomeric species of hIAPP contribute to the deleterious cellular effect by binding to bilipidic membranes leading to cell membrane leakage (Buchanan et al. 2013; Cao et al. 2013; Gurlo et al. 2010; Jayasinghe and Langen 2007; Jelinek and Sheynis 2010; Khemtemourian et al. 2008). PICUP assays were performed to determine the effect of NSAIDs on the oligomerization of hIAPP. The potent NSAIDs in affecting hIAPP aggregate were tested at a molar ratio of 1:5. Without NSAID and irradiation treatments, hIAPP was predominantly in a monomeric state. When hIAPP was subjected to light exposure, a mixture of monomer, dimer, trimer, tetramer and higher oligomers was obtained (Fig. 3), illustrating the strong oligomerization potential of hIAPP. The oligomerization of hIAPP was inhibited for samples treated with resveratrol and silibinin, consistent with previous experiments (Cheng et al. 2012; Jiang et al. 2011).

The oligomerization of hIAPP was abrogated following a treatment with diclofenac. The second most potent inhibitor was sulindac. The dimeric state was observed in samples treated with the oxicam family (meloxicam, piroxicam and tenoxicam). Niflumic acid, nimesulide and phenylbutazone were able to partially block the oligomerization process.

\section{NSAIDs protect INS-1 cells from toxic hIAPP fibrils}

The potential protective effect of NSAIDs against hIAPP fibrils cytotoxicity was investigated. Pre-incubated hIAPP was added to INS-1 cells for $24 \mathrm{~h}$ in the presence or absence of increasing concentration of NSAIDs (Fig. 4). Resveratrol protected cells at 12.5 $\mu \mathrm{M}$ (molar ratio 1:5). The cell viability was significantly preserved with silibinin, diclofenac, meloxicam, phenylbutazone, sulindac and tenoxicam at a molar ratio of 1:10. 
These drugs were not toxic at a higher concentration $(50 \mu \mathrm{M}$, molar ratio of 1:20). Higher concentrations of meloxicam and resveratrol $(50 \mu \mathrm{M})$ did not have a protective effect, whereas lower concentrations $(25 \mu \mathrm{M})$ reduced the deleterious effect of hIAPP fibrils. The protective effect of resveratrol and meloxicam against hIAPP aggregation has a narrow therapeutic window. Niflumic acid and nimesulide are toxic at concentrations affecting hIAPP aggregation. Thus, a protective effect of these drugs was not observed.

\section{Discussion}

The global prevalence of type 2 diabetes among adults population worldwide was approximated to be $9 \%$ in 2014 (www.who.int/mediacentre/factsheets/fs312/en/). Up to 1.5 million deaths were estimated in 2012 to be directly attributed to type 2 diabetes (www.who.int/mediacentre/factsheets/fs312/en/). There is a compelling need to improve the prevention and/or treatment of type 2 diabetes. IAPP possesses a potent ability to aggregate into mature fibrils in the islet of Langerhans (Buchanan et al. 2013). Mature linear fibrils and intermediate forms, such as oligomers, provoke cell damage, oxidative stress and apoptosis (Abedini and Schmidt 2013; Cao et al. 2013; Gurlo et al. 2010; Jayasinghe and Langen 2007; Khemtemourian et al. 2008). Amyloid deposition contributes to the $\beta$-cell loss and the progression of the disease (Abedini and Schmidt 2013; Hoppener et al. 2002; Jaikaran and Clark 2001; Kamata et al. 2014). Treatment with inhibitors of hIAPP fibril or oligomer formation presents a potential new pharmacotherapeutic strategy for the management of type 2 diabetes (Cheng et al. 2013; Frydman-Marom et al. 2011; Hard and Lendel 2012; Porat et al. 2006). 
Non-steroidal anti-inflammatory drugs (NSAIDs) have been used in a plethora of inflammatory conditions based on the inhibition of COX-2. There are contradictory reports in regard to the amyloid inhibitory effect of NSAIDs in Alzheimer's disease (AD) (Browne et al. 2006; Cole et al. 2004; Dong et al. 2014; Hillmann et al. 2012; Lim et al. 2000; McKee et al. 2008; Netland et al. 1998; Yan et al. 2003). Previous investigations reported that the $\mathrm{A} \beta$-amyloid induces inflammation, but the inflammatory responses occur earlier than the formation of the senile plaque (Cole et al. 2004). The physiopathology underlying $\mathrm{AD}$ involves an inflammatory process that has not been fully understood and clinical studies have been reported conflicting data (Browne et al. 2006; Cole et al. 2004; Dong et al. 2014; Hillmann et al. 2012; Lim et al. 2000; McKee et al. 2008; Netland et al. 1998; Yan et al. 2003). Rofecoxib, a selective COX-2 inhibitor, failed to reduce the progression of cognitive impairment in patients suffering from mild or moderate $\mathrm{AD}$ (Aisen et al. 2003). However, another study reported that COX-2 inhibition improves the suppression of memory associated with $A \beta$-amyloid deposition in patients with $\mathrm{AD}$. In a transgenic mouse model of $\mathrm{AD}$, ibuprofen, a non-selective $\mathrm{COX}-2$ inhibitor, reduced AD-type pathologic change after 6 months of treatment in comparison with an untreated control group (Lim et al. 2000). Whether selective COX-2 inhibitors have clinical benefit remains to be elucidated.

There are limits to the interpretation of each assay that was performed, hence it is critical to consider the results of the different assays altogether before drawing conclusions. This study highlights compounds and structures of potential interest. For practical purposes, assays were completed within few hours (shorter and longer kinetics). 
ThT assays can be optimized by simple variations of initial testing conditions, compromising between physiologically relevant conditions and the need for a relatively fast reaction. When high-throughput screening of small molecules in relation to aggregation is used, it is important to complement the study with other assays, particularly a cell-based assay. Drugs may be capable of displacing ThT binding, resulting in false positives (false hit compound). Which is why, we complemented the Thioflavin T-based fluorescence assays with the Far-UV circular discroism spectrometry, the photo-induced cross-linking (PICUP) assay and a biological assay. There are some limits in the interpretation of CD spectra for the apparent decrease at $220 \mathrm{~nm}$ due to the absorbance of the inhibitors, which stresses the importance of performing multiple assays before drawing conclusions on the potential efficacy of compounds. The cell-based assay used in our study involved pre-formed hIAPP amyloid before the drug challenge. Consequently, the effective drugs must be able to destabilize the fibril state to demonstrate a cytoprotective effect and/or impede the activation of apoptosis.

Few studies have evaluated the NSAIDs potential to abrogate the formation of fibrils. A series of analogues of diclofenac were effective in vitro in inhibiting the transthyretin fibrillization (Oza et al. 2002). In our study, several NSAIDs, such as diclofenac, phenylbutazone, sulindac and the oxicam representatives, exerted a significant inhibitory effect on fibril formation and delayed the structural transition of hIAPP. Meloxicam and sulindac were the most potent inhibitors of fibrillization, whereas diclofenac and sulindac were more potent in abrogating oligomerization of hIAPP. They protected pancreatic INS-1 cell from the deleterious effect of hIAPP fibrils. Ketorolac was not effective compounds, consistent with previous studies (Tu et al. 2014). 
The diclofenac derivatives prepared in the transthyretin amyloid fibril formation study depicted structure-activity relationships, applicable to impedance of hIAPP aggregation (Oza et al. 2002). Diclofenac and its related derivatives bind to the retinol binding pocket of TTR via computational docking. However, other interactions and targets are possible and we hypothesized that these molecules act as universal amyloid inhibitors, such as polyphenols, by inhibiting aggregation with a combination of structural rigidity and aromatic stacking. This study highlighted the requirement of a carboxylic acid directly attached to the benzene ring or separated with a methylene (Oza et al. 2002). In the second column of Figure 5 display the potent molecules that bear a carboxylic acid or sulfonamide in the current study. The protection of the carboxylic acid moiety, found in aceclofenac, abolished the activity to compare with diclofenac. To gain further information, it would be interesting to study the impact of acidic moieties with various pKas on hIAPP amyloidosis. Another information arising from the transthyretin study is the chlorines attached to the aromatic ring that bind to the protein (Oza et al. 2002). The chlorines were either positioned symmetrically in ortho or metha to provide binding, whereas their absence abolished the activity (Oza et al. 2002). Adding a carboxylic acid in para allowed an additional electrostatic interaction with the protein transthyretin (Oza et al. 2002). Herein, the NSAIDs molecular screening on hIAPP fibrils formation led to similar conclusions regarding the substitution patterns on the benzene ring. Interestingly, the aromatic ring of nimesulide is devoid of halides and niflumic acid benzene bears a trifluoromethyl group. Niflumic acid and nimesulide were less potent than diclofenac. Sulindac has a similar fibril inhibition activity to diclofenac. The aromatic ring has a methylsulfinyl moiety in para, not found in ketorolac, suggesting that 
an electron donor is required for fibril inhibition and could be important in the absence of halides.

The structure-activity relationships between diclofenac, niflumic acid, nimesulide, and their fibril inhibition activities against hIAPP underline the importance of a negatively charged substituent between the aromatic rings (Fig. 5). Sulindac has a double bound that can be delocalized easily to provide electrons, considering the electronic resonance. Sulindac has similarity in structure with the exception of an indenyl moiety, suggesting that the benzene ring could be substituted by a fused ring or heterocyclic aromatic ring. Amyloid inhibitors bear aromatic moieties that can potentially be stacked between other aromatic residues from the protein and abrogate the self-assembly of oligomers (Cheng et al. 2013; Frydman-Marom et al. 2011; Hard and Lendel 2012; Porat et al. 2006). The aromatic structure found in the diarylamine (second column Fig. 5) and oxicam scaffold (first column Fig. 5) abrogates the oligomerization of hIAPP potentially by preventing the aromatic interactions between the aromatic residues of hIAPP.

Phenylbutazone and the oxicam family provide a different chemistry scaffold than the diarylamine scaffold (diclofenac), to prepare other derivatives (first column of Fig. 5). Among the oxicam family members, meloxicam had the strongest fibril inhibition activity and tenoxicam provided the highest survival when INS-1 cells were challenged with toxic fibrils. Tenoxicam bears a 2,3-dihydrothiophene that is substituted by a benzene moiety in meloxicam and piroxicam. Meloxicam differs from Piroxicam and tenoxicam, having a 5-methyl-2-thiazolyl rather than a pyridine moiety. However, the 5methyl-2-thiazolyl moiety could potentially explain the deleterious effect of meloxicam 
on INS-1 cells and further study is needed to confirm this hypothesis. The molecular structure of phenylbutazone is quite similar to the oxicam family with a heterocycle bearing two amines and two carbonyls, resulting in nucleophilicity. Phenylbutazone is very toxic to human, causing anaplastic anemia and liver damage (Goodman et al. 2011). However, it has been extensively used in veterinary medicine (Kahn et al. 2010). Chemical modification will be required not only to improve its efficacy toward hIAPP fibrillization but to modify the toxicologic effect in humans.

The present in vitro study demonstrates that several NSAIDs inhibit amyloid formation. Multiple probes were used to study the inhibition of the toxic hIAPP assembly. It has been reported that oligomers are important entities involved in the mechanism of hIAPP amyloid cytotoxicity. The most potent drugs against hIAPP oligomerization were diclofenac and sulindac. Diclofenac, meloxicam, phenylbutazone, piroxicam, sulindac and tenoxicam conferred cell protection against toxic fibrils. Chemical scaffold from the enolic acid class (oxicam and phenylbutazone) and the acetic acid class (diclofenac, sulindac) could be modified to generate new inhibitors of hIAPP aggregation. NSAID derived compound scaffolds are interesting potential candidates for the development of type 2 diabetes treatment.

\section{Acknowledgment}

This work was supported by a grant from Diabètes Québec. We are very grateful to Mr. Frédéric Berthiaume for the technical advice and Dr. Mostafa Hatam for the peptide synthesis. 


\section{References}

Abedini, A., and Schmidt, A.M. 2013. Mechanisms of islet amyloidosis toxicity in type 2 diabetes. FEBS Lett. 587(8): 1119-1127. doi: 10.1016/j.febslet.2013.01.017.

Aisen, P.S., Schafer, K.A., Grundman, M., Pfeiffer, E., Sano, M., Davis, K.L., Farlow, M.R., Jin, S., Thomas, R.G., Thal, L.J., and Alzheimer's Disease Cooperative, S. 2003. Effects of rofecoxib or naproxen vs placebo on Alzheimer disease progression: a randomized controlled trial. J. Am. Med. Assoc. 289(21): 2819-2826. doi: 10.1001/jama.289.21.2819.

Bitan, G., and Teplow, D.B. 2004. Rapid photochemical cross-linking--a new tool for studies of metastable, amyloidogenic protein assemblies. Accounts of C Research, 37(6): 357-364. doi: 10.1021/ar0002141.

Brender, J. R., Krishnamoorthy, J., Sciacca, M. F. M., Vivekanandan, S., D'Urso, L., Chen, J., La Rosa, C., and Ramamoorthy, A. 2015. Probing the Sources of the Apparent Irreproducibility of Amyloid Formation: Drastic Changes in Kinetics and a Switch in Mechanism Due to Micelle like Oligomer Formation at Critical Concentrations of IAPP. J. Phys. Chem. B 119(7), 2886-2896. doi:10.1021/jp511758w.

Browne, K.D., Iwata, A., Putt, M.E., and Smith, D.H. 2006. Chronic ibuprofen administration worsens cognitive outcome following traumatic brain injury in rats. Exp. Neurol. 201(2): 301-307. doi: 10.1016/j.expneurol.2006.04.008. 
Buchanan, L.E., Dunkelberger, E.B., Tran, H.Q., Cheng, P.N., Chiu, C.C., Cao, P., Raleigh, D.P., de Pablo, J.J., Nowick, J.S., and Zanni, M.T. 2013. Mechanism of IAPP amyloid fibril formation involves an intermediate with a transient beta-sheet. Proc. Natl. Acad. Sci. U. S. A. 110(48): 19285-19290. doi: 10.1073/pnas.1314481110.

Buell, A.K., Dobson, C.M., Knowles, T.P., and Welland, M.E. 2010. Interactions between amyloidophilic dyes and their relevance to studies of amyloid inhibitors. Biophys. J. 99(10): 3492-3497. doi: 10.1016/j.bpj.2010.08.074.

Cao, P., Abedini, A., Wang, H., Tu, L.H., Zhang, X., Schmidt, A.M., and Raleigh, D.P. 2013. Islet amyloid polypeptide toxicity and membrane interactions. Proc. Natl. Acad. Sci. U. S. A. 110(48): 19279-19284. doi: 10.1073/pnas.1305517110.

Cheng, B., Gong, H., Li, X., Sun, Y., Zhang, X., Chen, H., Liu, X., Zheng, L., and Huang, K. 2012. Silibinin inhibits the toxic aggregation of human islet amyloid polypeptide. Biochem. Biophys. Res. Commun. 419(3): 495-499. doi: 10.1016/j.bbrc.2012.02.042.

Cheng, B., Gong, H., Xiao, H., Petersen, R.B., Zheng, L., and Huang, K. 2013. Inhibiting toxic aggregation of amyloidogenic proteins: a therapeutic strategy for protein misfolding diseases. Biochim. Biophys. Acta, 1830(10): 4860-4871. doi: 10.1016/j.bbagen.2013.06.029.

Cole, G.M., Morihara, T., Lim, G.P., Yang, F., Begum, A., and Frautschy, S.A. 2004. NSAID and antioxidant prevention of Alzheimer's disease: lessons from in vitro and animal models. Ann. N. Y. Acad. Sci. 1035: 68-84. doi: 10.1196/annals. 1332.005. 
Dong, Z., Yan, L., Huang, G., Zhang, L., Mei, B., and Meng, B. 2014. Ibuprofen partially attenuates neurodegenerative symptoms in presenilin conditional double-knockout mice. Neuroscience, 270: 58-68. doi: 10.1016/j.neuroscience.2014.03.048.

Fortin, J., Patenaude, A., Deschesnes, R.G., Cote, M.F., Petitclerc, E., and C-Gaudreault, R. 2010. ASK1-P38 Pathway is Important for Anoikis Induced by MicrotubuleTargeting Aryl Chloroethylureas. J. Pharm. Pharm. Sci. 13(2): 175-190.

Frydman-Marom, A., Shaltiel-Karyo, R., Moshe, S., and Gazit, E. 2011. The generic amyloid formation inhibition effect of a designed small aromatic beta-breaking peptide. Amyloid, 18(3): 119-127. doi: 10.3109/13506129.2011.582902.

Goodman, L.S., Brunton, L.L., Chabner, B., and Knollmann, B.C. 2011. Goodman \& Gilman's the pharmacological basis of therapeutics. McGraw-Hill Medical,, New York ; Toronto.

Gurlo, T., Ryazantsev, S., Huang, C.J., Yeh, M.W., Reber, H.A., Hines, O.J., O'Brien, T.D., Glabe, C.G., and Butler, P.C. 2010. Evidence for proteotoxicity in beta cells in type 2 diabetes: toxic islet amyloid polypeptide oligomers form intracellularly in the secretory pathway. Am. J. Pathol. 176(2): 861-869. doi: 10.2353/ajpath.2010.090532.

Hard, T., and Lendel, C. 2012. Inhibition of amyloid formation. J. Mol. Biol. 421(4-5): 441-465. doi: 10.1016/j.jmb.2011.12.062.

Hillmann, A., Hahn, S., Schilling, S., Hoffmann, T., Demuth, H.U., Bulic, B., SchneiderAxmann, T., Bayer, T.A., Weggen, S., and Wirths, O. 2012. No improvement after 
chronic ibuprofen treatment in the 5XFAD mouse model of Alzheimer's disease. Neurobiology of aging, 33(4): 833 e839-850. doi: 10.1016/j.neurobiolaging.2011.08.006.

Hoppener, J.W., Nieuwenhuis, M.G., Vroom, T.M., Ahren, B., and Lips, C.J. 2002. Role of islet amyloid in type 2 diabetes mellitus: consequence or cause? Mol. Cell. Endocrinol. 197(1-2): 205-212.

Jaikaran, E.T., and Clark, A. 2001. Islet amyloid and type 2 diabetes: from molecular misfolding to islet pathophysiology. Biochim. Biophys. Acta, 1537(3): 179-203.

Jayasinghe, S.A., and Langen, R. 2007. Membrane interaction of islet amyloid polypeptide. Biochim. Biophys. Acta, 1768(8): 2002-2009. doi: 10.1016/j.bbamem.2007.01.022.

Jelinek, R., and Sheynis, T. 2010. Amyloid - membrane interactions: experimental approaches and techniques. Current protein \& peptide science, 11(5): 372-384.

Jiang, P., Li, W., Shea, J.E., and Mu, Y. 2011. Resveratrol inhibits the formation of multiple-layered beta-sheet oligomers of the human islet amyloid polypeptide segment 22-27. Biophys. J. 100(6): 1550-1558. doi: 10.1016/j.bpj.2011.02.010.

Kahn, C.M., Line, S., and Merck \& Co. 2010. The Merck veterinary manual. 10th ed. Merck \& Co., Whitehouse Station, N.J.

Kamata, K., Mizukami, H., Inaba, W., Tsuboi, K., Tateishi, Y., Yoshida, T., and Yagihashi, S. 2014. Islet amyloid with macrophage migration correlates with 
augmented beta-cell deficits in type 2 diabetic patients. Amyloid, 21(3): 191-201. doi: 10.3109/13506129.2014.937857.

Khemtemourian, L., Killian, J.A., Hoppener, J.W., and Engel, M.F. 2008. Recent insights in islet amyloid polypeptide-induced membrane disruption and its role in beta-cell death in type 2 diabetes mellitus. Exp. Diabetes Res. 2008: 421287. doi: $10.1155 / 2008 / 421287$

Lim, G.P., Yang, F., Chu, T., Chen, P., Beech, W., Teter, B., Tran, T., Ubeda, O., Ashe, K.H., Frautschy, S.A., and Cole, G.M. 2000. Ibuprofen suppresses plaque pathology and inflammation in a mouse model for Alzheimer's disease. J. Neurosci. 20(15): $5709-5714$

Luca, S., Yau, W. M., Leapman, R., and Tycko, R. 2007. Peptide conformation and supramolecular organization in amylin fibrils: Constraints from solid-state NMR. Biochemistry, 46(47): 13505-13522. doi: 10.1021/bi701427q.

Mishra, R., Geyer, M., and Winter, R. 2009. NMR spectroscopic investigation of early events in IAPP amyloid fibril formation. Chembiochem, 10(11): 1769-1772. Doi: 10.1002/cbic. 200900237 .

McKee, A.C., Carreras, I., Hossain, L., Ryu, H., Klein, W.L., Oddo, S., LaFerla, F.M., Jenkins, B.G., Kowall, N.W., and Dedeoglu, A. 2008. Ibuprofen reduces Abeta, hyperphosphorylated tau and memory deficits in Alzheimer mice. Brain Res. 1207: 225-236. doi: 10.1016/j.brainres.2008.01.095. 
Netland, E.E., Newton, J.L., Majocha, R.E., and Tate, B.A. 1998. Indomethacin reverses the microglial response to amyloid beta-protein. Neurobiology of aging, 19(3): 201204.

O'Brien, T.D., Butler, P.C., Westermark, P., and Johnson, K.H. 1993. Islet amyloid polypeptide: a review of its biology and potential roles in the pathogenesis of diabetes mellitus. Vet. Pathol. 30(4): 317-332.

Oza, V.B., Smith, C., Raman, P., Koepf, E.K., Lashuel, H.A., Petrassi, H.M., Chiang, K.P., Powers, E.T., Sachettinni, J., and Kelly, J.W. 2002. Synthesis, structure, and activity of diclofenac analogues as transthyretin amyloid fibril formation inhibitors. J. Med. Chem. 45(2): 321-332.

Padrick, S. B., and Miranker, A. D. 2002. Islet amyloid: Phase partitioning and secondary nucleation are central to the mechanism of fibrillogenesis. Biochemistry, 41(14), 4694-4703. doi: 10.1021/bi0160462.

Paulsson, J.F., Benoit-Biancamano, M.O., Schaffer, L., and Dahl, K. 2011. Ferret islet amyloid polypeptide (IAPP): characterization of in vitro and in vivo amyloidogenicity. Amyloid, 18(4): 222-228. doi: 10.3109/13506129.2011.627956.

Porat, Y., Abramowitz, A., and Gazit, E. 2006. Inhibition of amyloid fibril formation by polyphenols: structural similarity and aromatic interactions as a common inhibition mechanism. Chemical biology \& drug design, 67(1): 27-37. doi: 10.1111/j.17470285.2005.00318.x. 
Reddy, A. S., Wang, L., Singh, S., Ling, Y. L., Buchanan, L., Zanni, M. T., Skinner, J. L., and de Pablo, J. J. 2010. Stable and Metastable States of Human Amylin in Solution. Biophysique journal, 99(7): 2208-2216. doi: 10.1016/j.bpj.2010.07.014.

Ruschak, A.M., and Miranker, A.D. 2007. Fiber-dependent amyloid formation as catalysis of an existing reaction pathway. Proc. Natl. Acad. Sci. U. S. A. 104(30): 12341-12346. doi: 10.1073/pnas.0703306104.

Shvadchak, V.V., Claessens, M.M.A.E., and Subramaniam, V. 2015. Fibril Breaking Accelerates alpha-Synuclein Fibrillization. J. Phys. Chem. B 119(5): 1912-1918. doi: 10.1021/jp5111604.

Sipe, J.D., Benson, M.D., Buxbaum, J.N., Ikeda, S., Merlini, G., Saraiva, M.J., and Westermark, P. 2014. Nomenclature 2014: Amyloid fibril proteins and clinical classification of the amyloidosis. Amyloid, 21(4): 221-224. doi: 10.3109/13506129.2014.964858.

Sreerama, N., and Woody, R.W. 2004. Computation and analysis of protein circular dichroism spectra. Meth. Enzymol. 383: 318-351. doi: 10.1016/S00766879(04)83013-1.

Suzuki, Y., Brender, J.R., Hartman, K., Ramamoorthy, A., and Marsh, E.N.G. 2012. Alternative Pathways of Human Islet Amyloid Polypeptide Aggregation Distinguished by F-19 Nuclear Magnetic Resonance-Detected Kinetics of Monomer Consumption. Biochemistry, 51 (41), 8154-8162. doi: 10.1021/bi3012548. 
Tu, L.H., Noor, H., Cao, P., and Raleigh, D.P. 2014. Aspirin, diabetes, and amyloid: reexamination of the inhibition of amyloid formation by aspirin and ketoprofen. ACS Chemical Biology, 9(7): 1632-1637. doi: 10.1021/cb500162w.

Westermark, P., Andersson, A., and Westermark, G.T. 2011. Islet amyloid polypeptide, islet amyloid, and diabetes mellitus. Physiol. Rev. 91(3): 795-826. doi: 10.1152/physrev.00042.2009.

Williamson, J.A., and Miranker, A.D. 2007. Direct detection of transient alpha-helical states in islet amyloid polypeptide. Protein Science, 16(1): 110-117. doi: 10.1110/ps.062486907.

Yan, Q., Zhang, J., Liu, H., Babu-Khan, S., Vassar, R., Biere, A.L., Citron, M., and Landreth, G. 2003. Anti-inflammatory drug therapy alters beta-amyloid processing and deposition in an animal model of Alzheimer's disease. J. Neurosci. 23(20): 75047509.

Yonemoto, I.T., Kroon, G.J., Dyson, H.J., Balch, W.E., and Kelly, J.W. 2008. Amylin proprotein processing generates progressively more amyloidogenic peptides that initially sample the helical state. Biochemistry, 47(37), 9900-9910. doi: 10.1021/bi800828u.

Zhang, X., Cheng, B., Gong, H., Li, C., Chen, H., Zheng, L., and Huang, K. 2011. Porcine islet amyloid polypeptide fragments are refractory to amyloid formation. FEBS Lett. 585(1): 71-77. doi: 10.1016/j.febslet.2010.11.050. 


\section{Figure captions}

Fig. 1. A Relative ThT fluorescence intensity of hIAPP with different effective drug treatments (silibinin, resveratrol, celecoxib, diclofenac, indomethacin, meloxicam, niflumic acid, nimesulide, phenylbutazone, piroxicam, sulindac, and tenoxicam) tested at a concentration of $100 \mu \mathrm{M}$ (longer agitation). ThT-fluorescence of hIAPP was assessed at $25^{\circ} \mathrm{C}$ in PBS buffer at a peptide concentration of $10 \mu \mathrm{M}$ and a molar ratio of $1: 10$. B Relative ThT fluorescence intensity of hIAPP with identical drug treatments obtained from a shorter agitation.

Fig. 2. Far-UV circular dichroism spectra of hIAPP recorded in the presence of the vehicle $\left(1 \%\right.$ HFIP) or different drug treatments. Spectra were recorded at $25^{\circ} \mathrm{C}$ in $\mathrm{PBS}$ buffer using hIAPP at $15 \mu \mathrm{M}$ and drug treatments at $25 \mu \mathrm{M}$ (molar ratio of 1:1.67). The incubation time were $0,15,30$ and $60 \mathrm{~min}$.

Fig. 3. Oligomerization status of hIAPP studied by the photo-induced cross linking (PICUP) assay. (a) Lane 1, hIAPP without irradiation; lane 2, hIAPP irradiated for 3 sec; lanes 3-4, hIAPP with positive controls irradiated for $3 \mathrm{sec}$. The molar ratio was 1:5, 0.25 $\mathrm{mM}$ of hIAPP and $1.25 \mathrm{mM}$ of positive controls (resveratrol and silibinin). (b) Lane 1, hIAPP irradiated for $3 \mathrm{sec}$; lanes 2-9, hIAPP with different drug treatment irradiated for 3 sec. The molar ratio was 1:5, $0.25 \mathrm{mM}$ of hIAPP and $1.25 \mathrm{mM}$ of drugs (diclofenac, meloxicam, niflumic acid, nimesulide, phenylbutazone, piroxicam, sulindac and tenoxicam). 
Fig. 4. INS-1 cell viability in the presence of hIAPP alone and hIAPP with different drug treatments, such as resveratrol, silibinin, diclofenac, meloxicam, niflumic acid, nimesulide, phenylbutazone, piroxicam, sulindac and tenoxicam, as determined by resazurin-based assays. hIAPP was tested at a concentration of $2.5 \mu \mathrm{M}$ and with effective concentrations $(12.5,25$ or $50 \mu \mathrm{M})$ of each drug. The molar ratios were 1:5, 1:10 and 1:20. The one-way analysis of variance with Dunnett's multiple comparison test showed significant differences between IAPP and several drug treatments $(*$ and ** are indicative of $p<0.05$ and $p<0.001$, respectively).

Fig. 5. Proposed structure-activity relationships between the acetic acid class (A) and between the enolic acid class (B).

\section{Abbreviations list:}

AD, Alzheimer's disease; COX, cyclooxygenase; hIAPP, human islet amyloid polypeptide; NSAID, non-steroidal anti-inflammatory. 
A
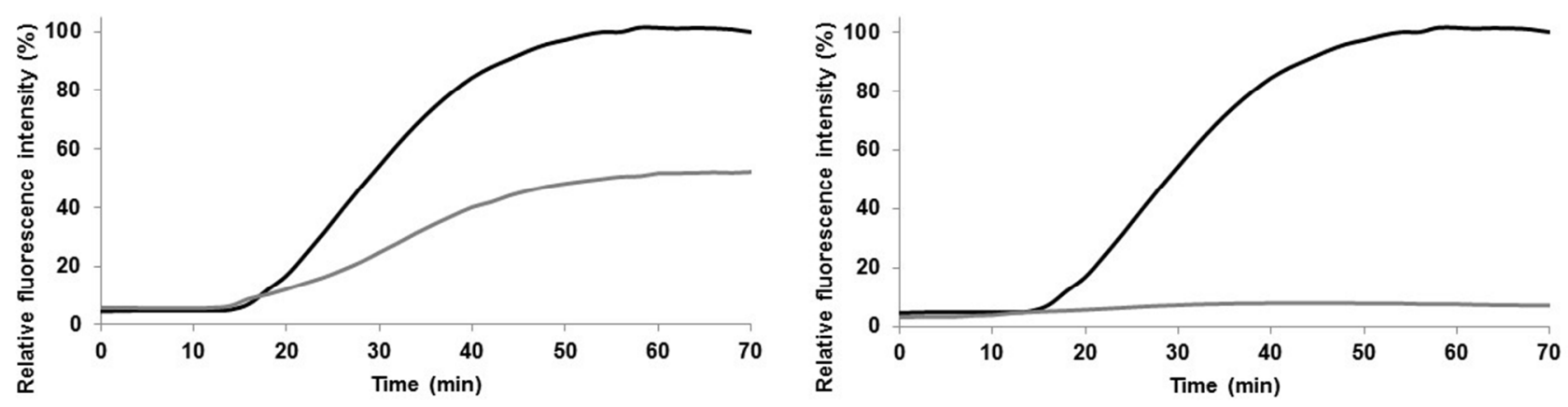

—CTRL - Silibinin
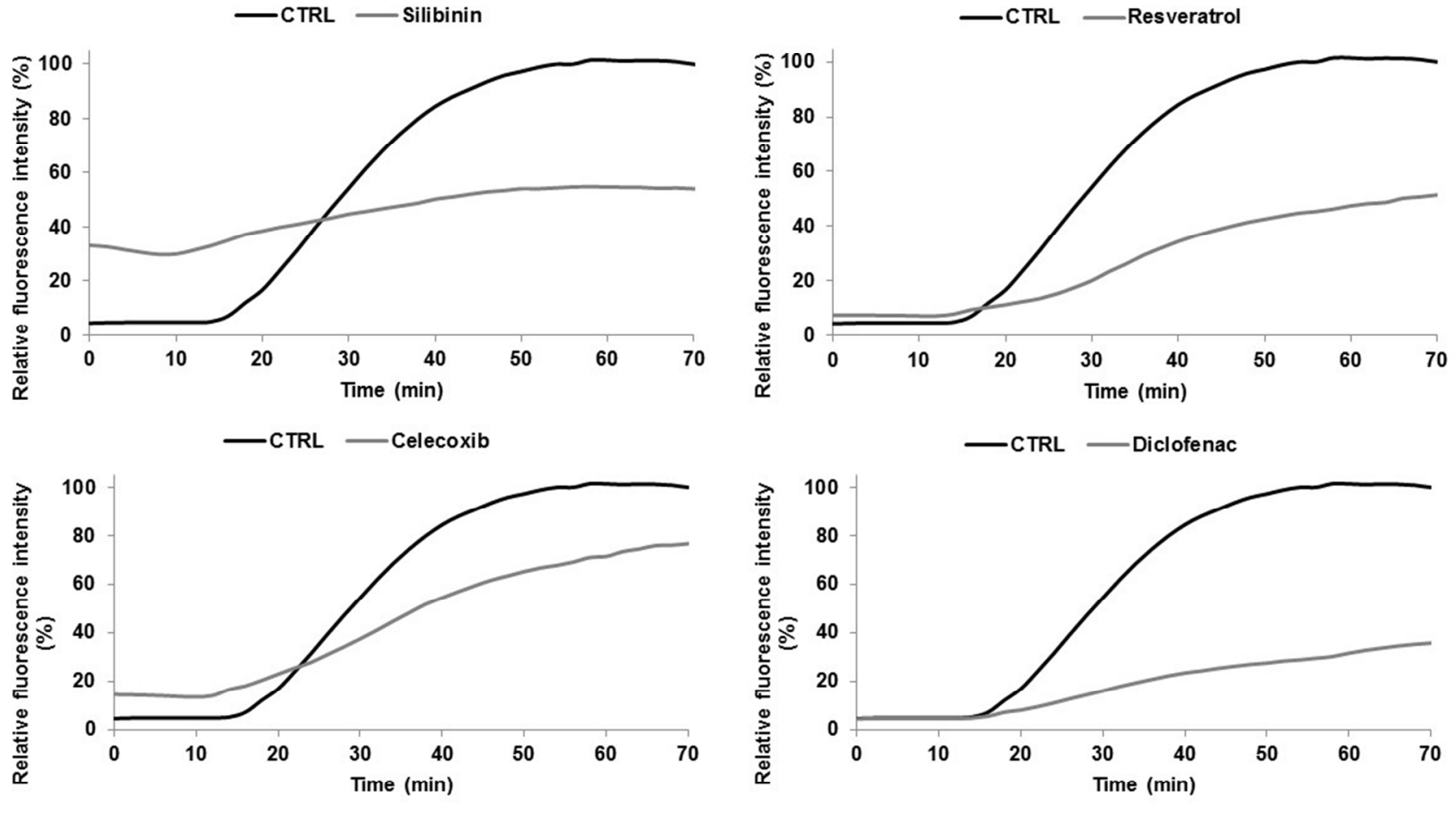

—CTRL Indomethacin

—CTRL Meloxicam 

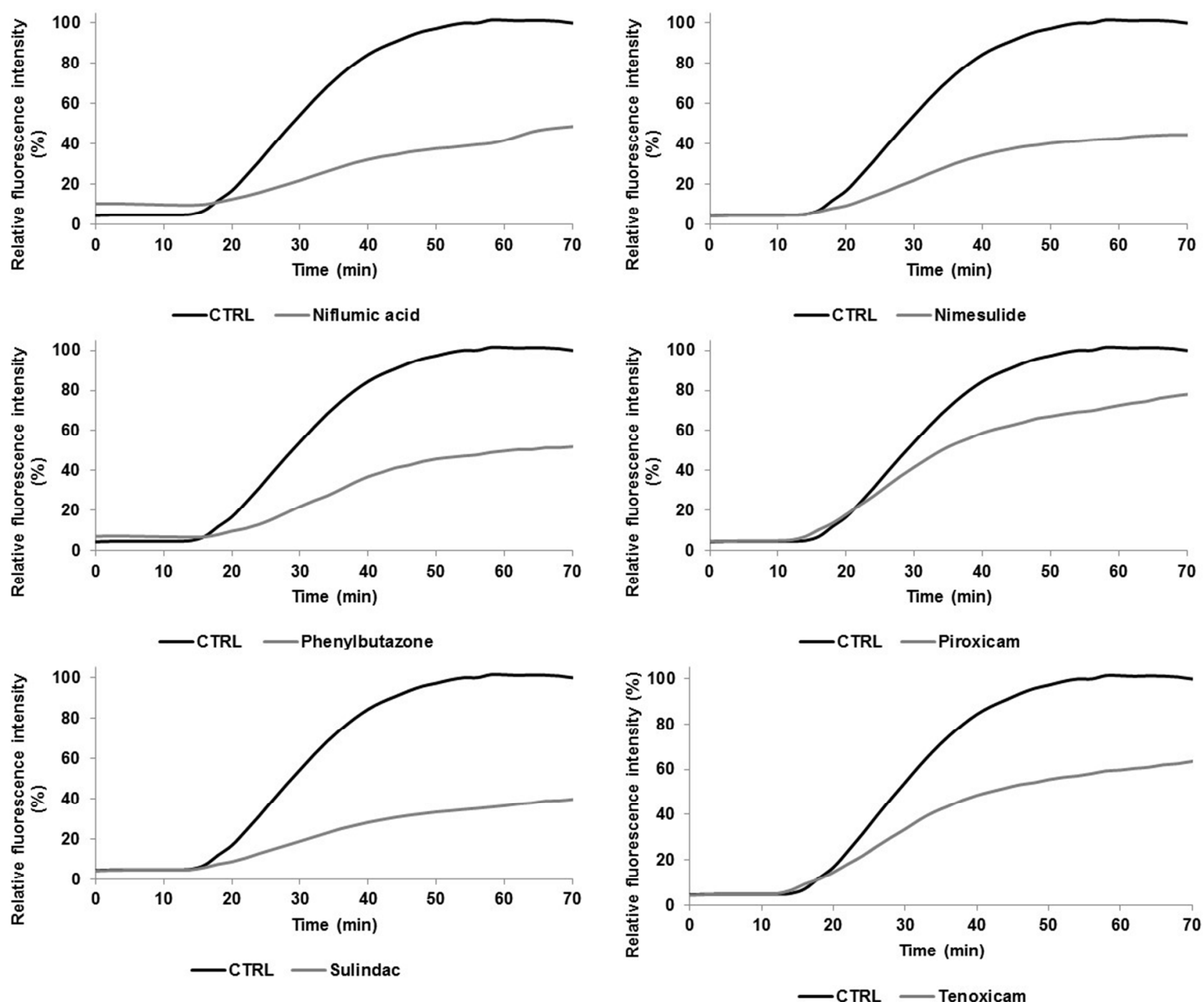
B
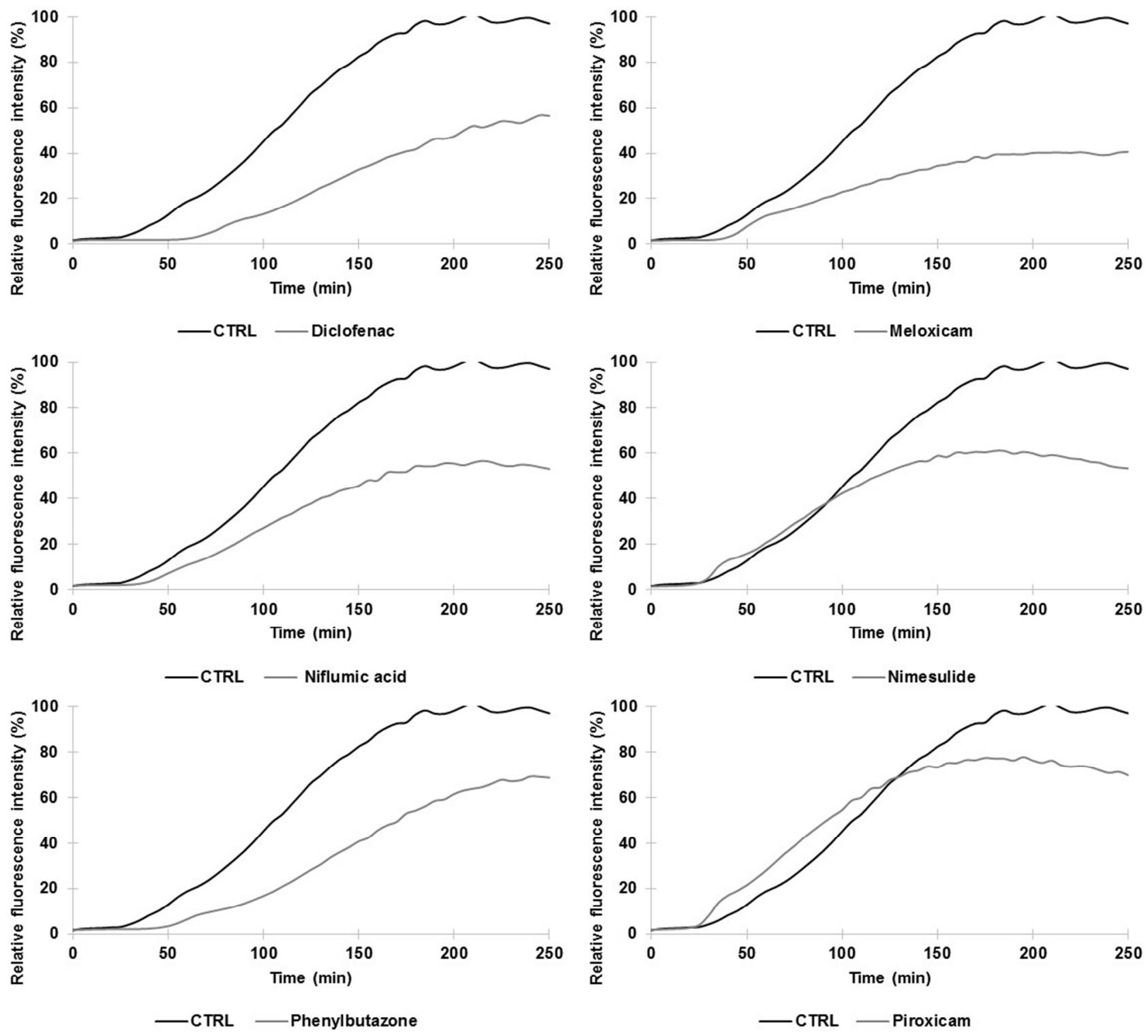

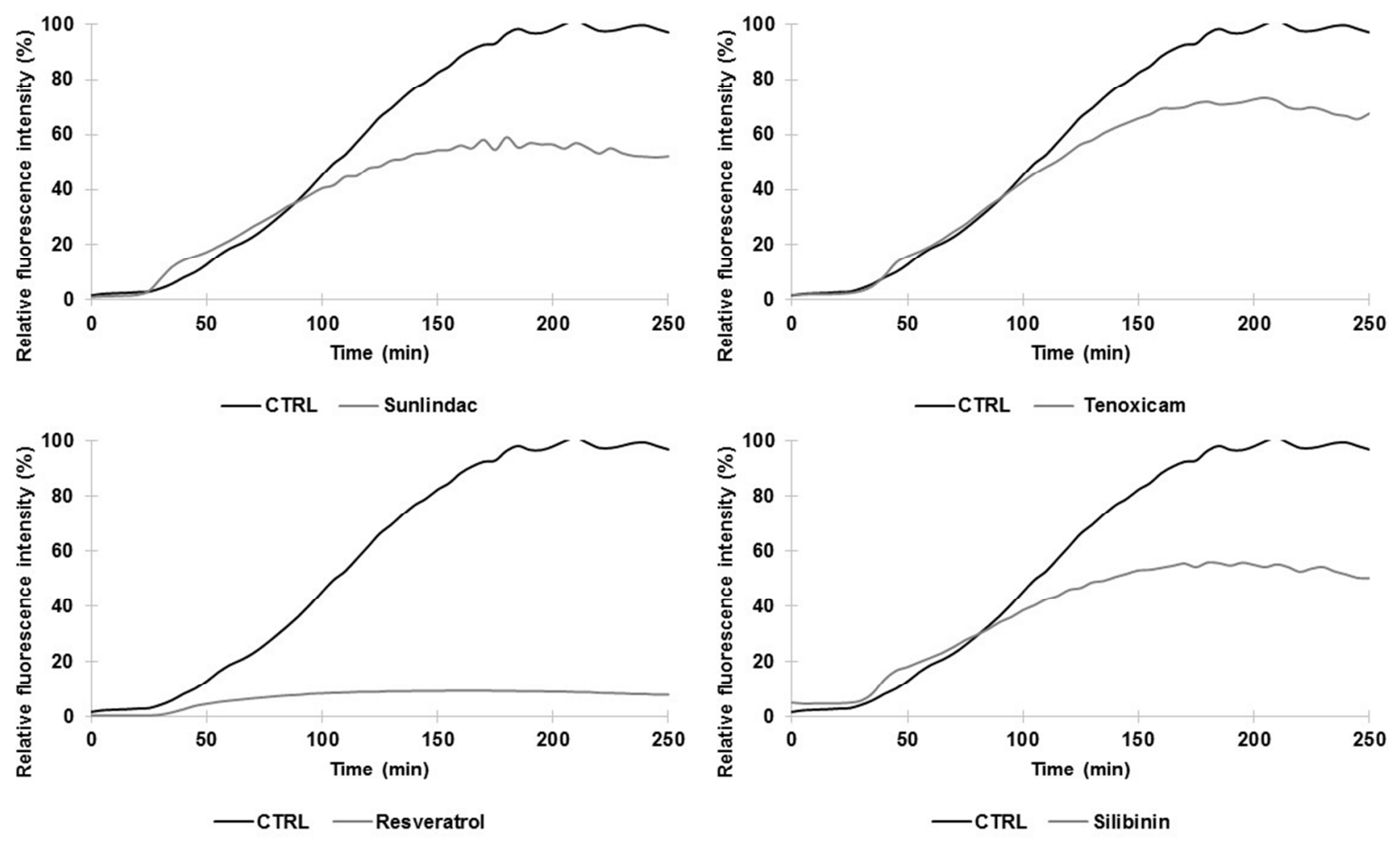


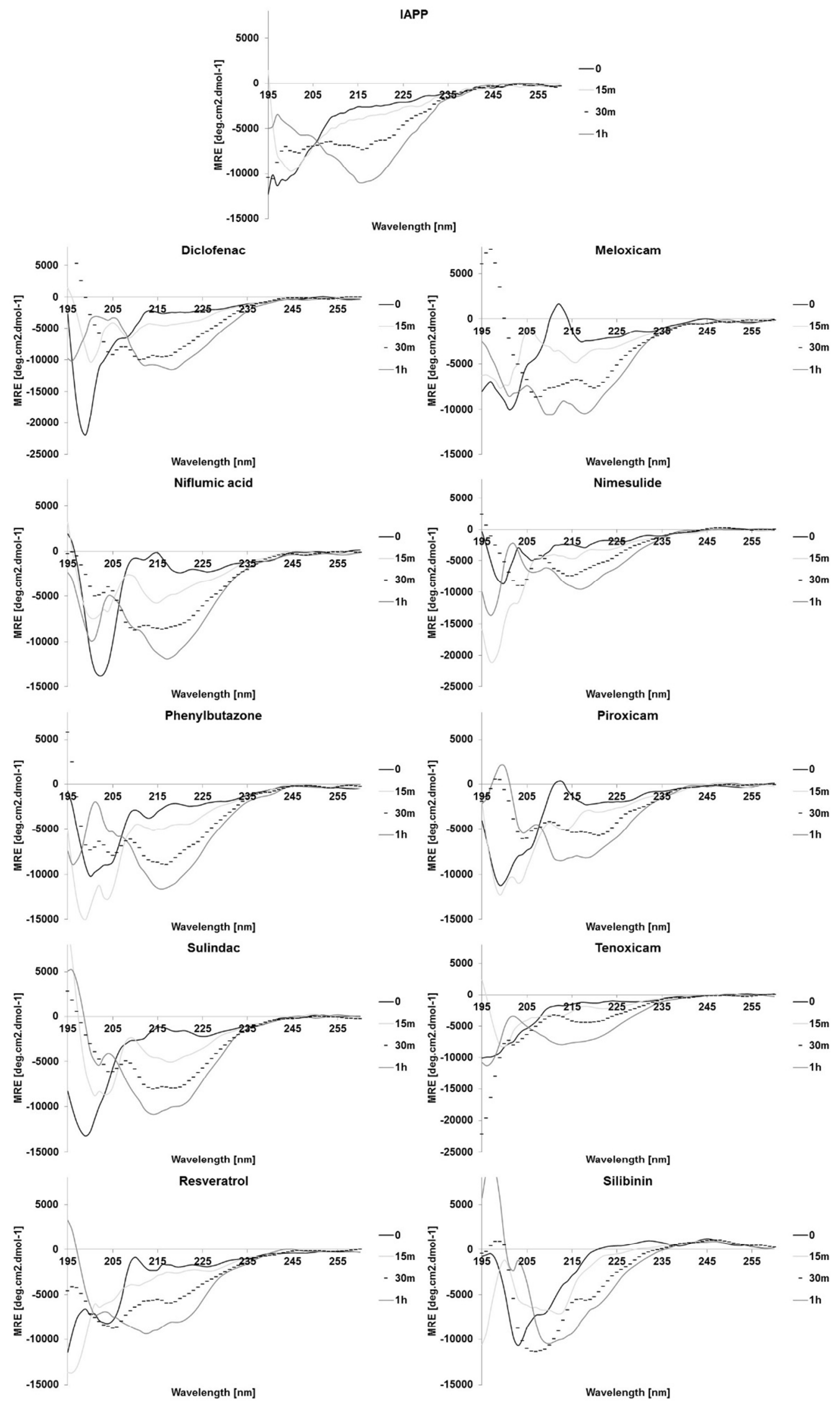


A B

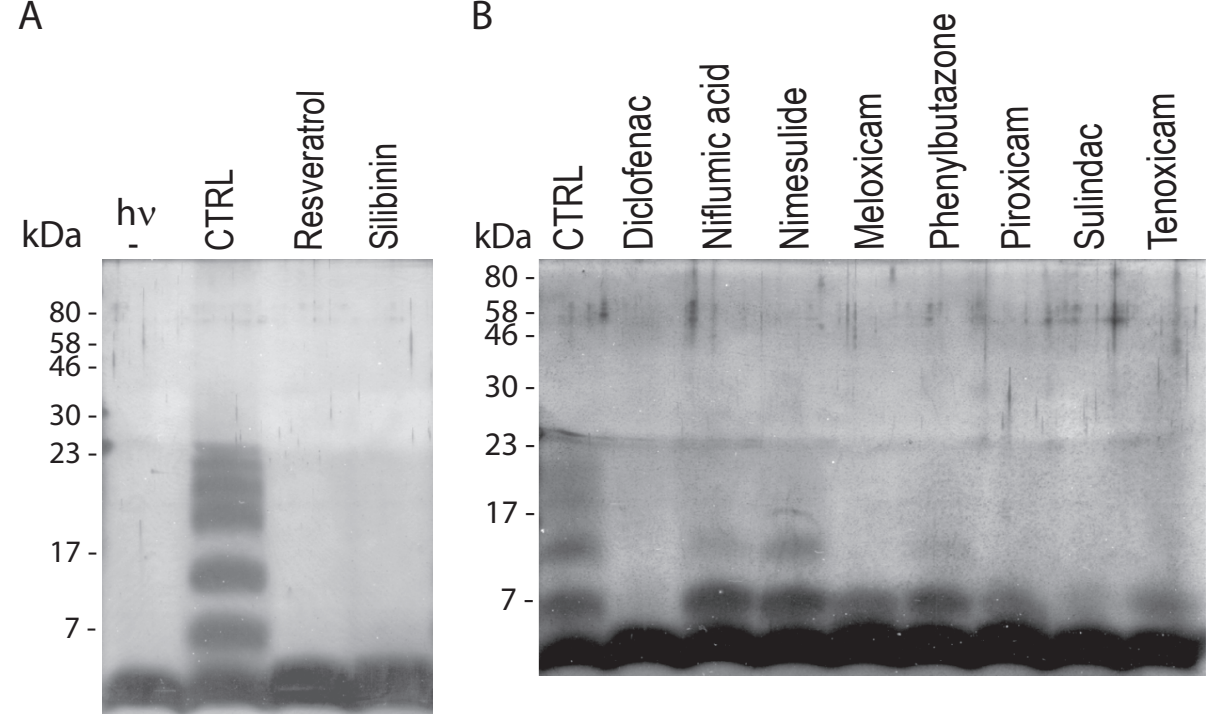




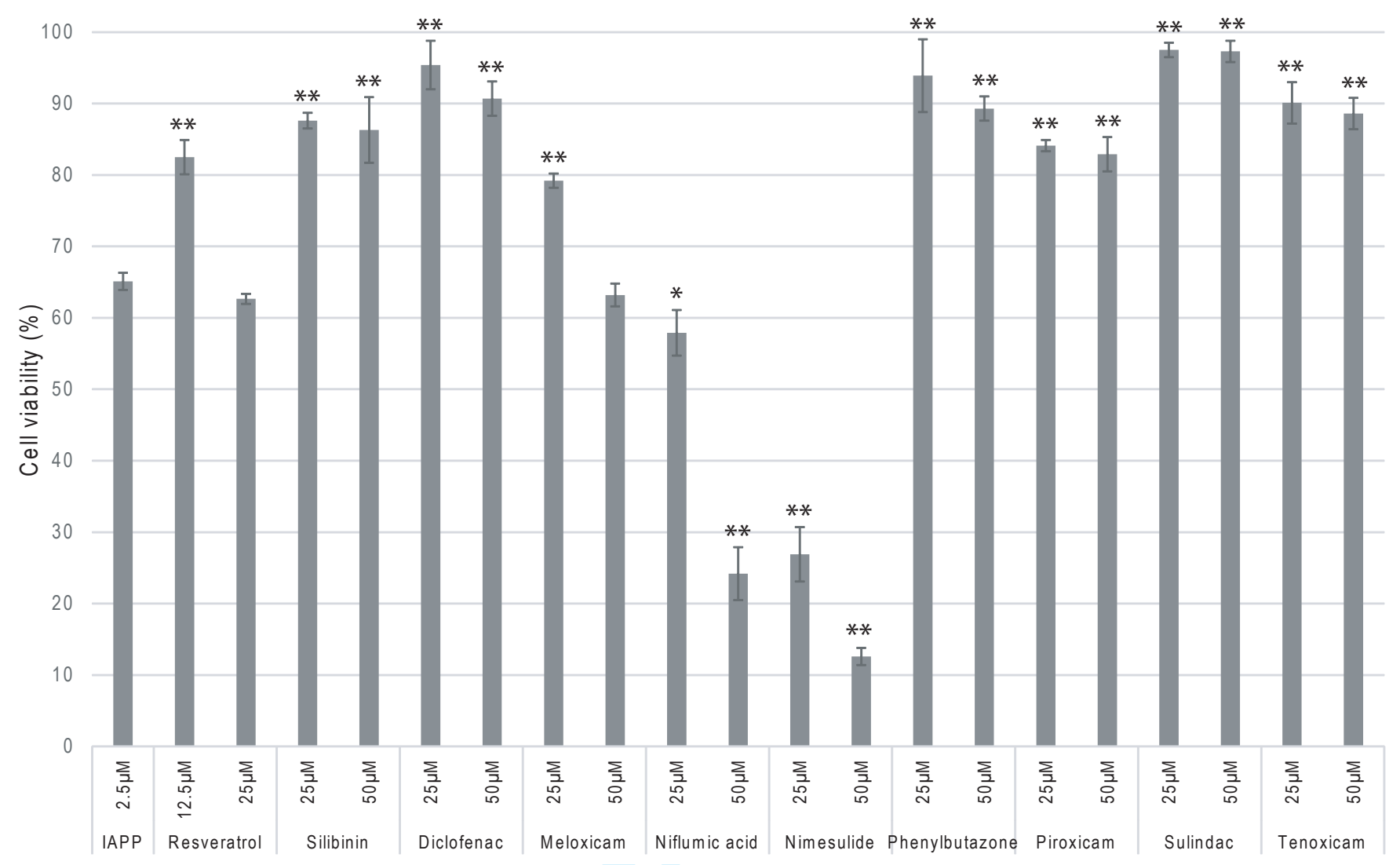


A B

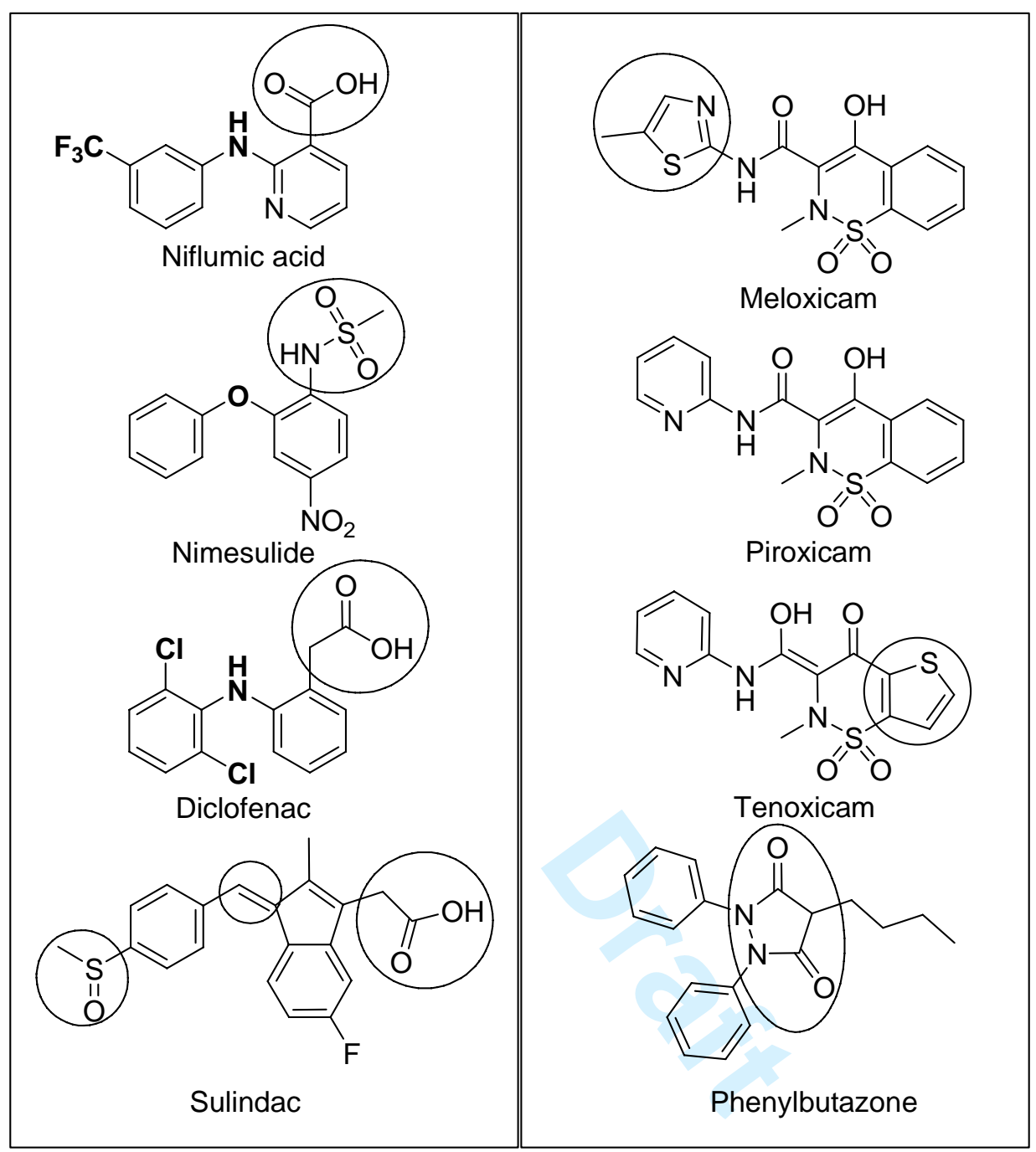


Table 1. Classification and molecular structure of positive controls and NSAIDs used in this study.

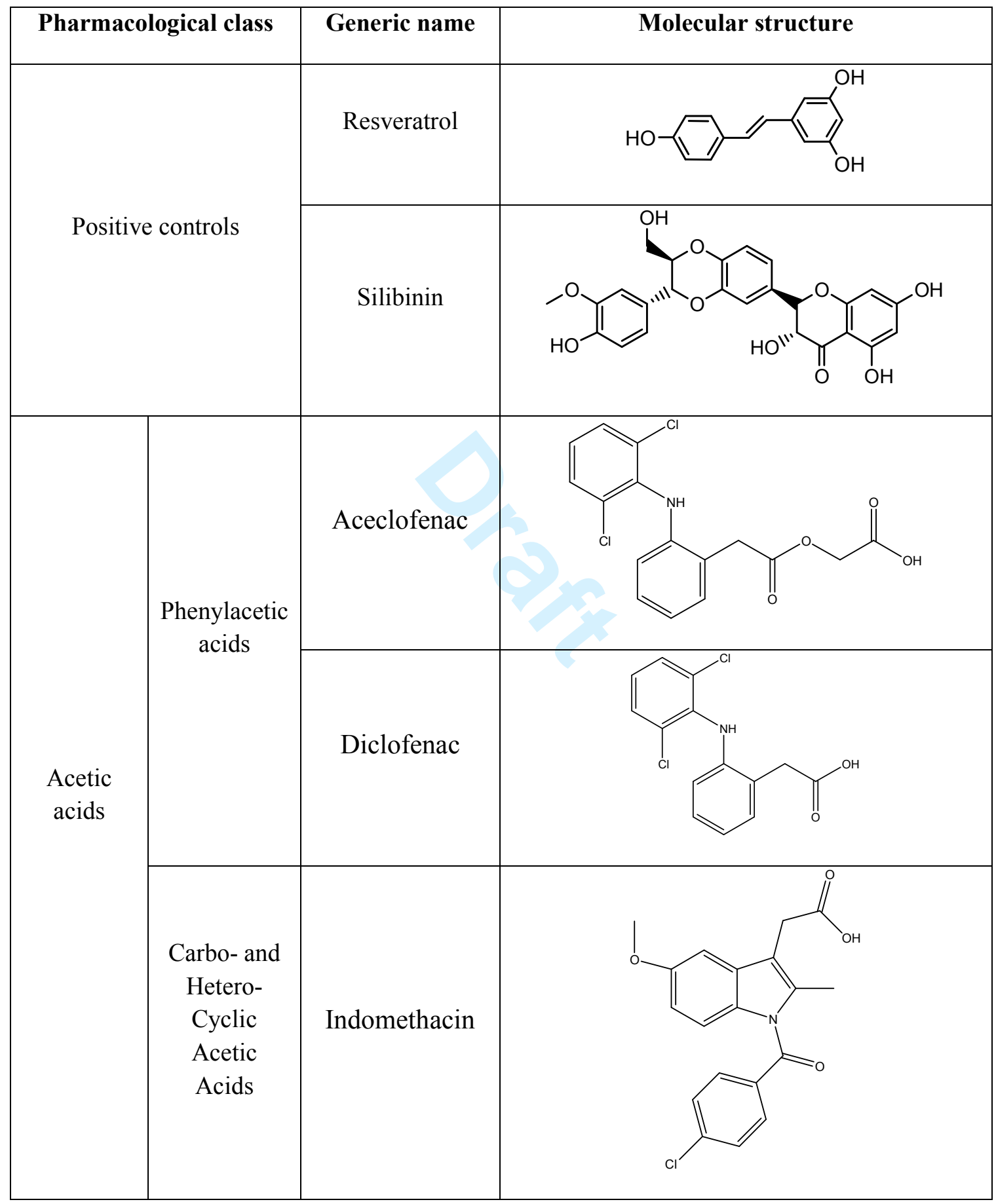




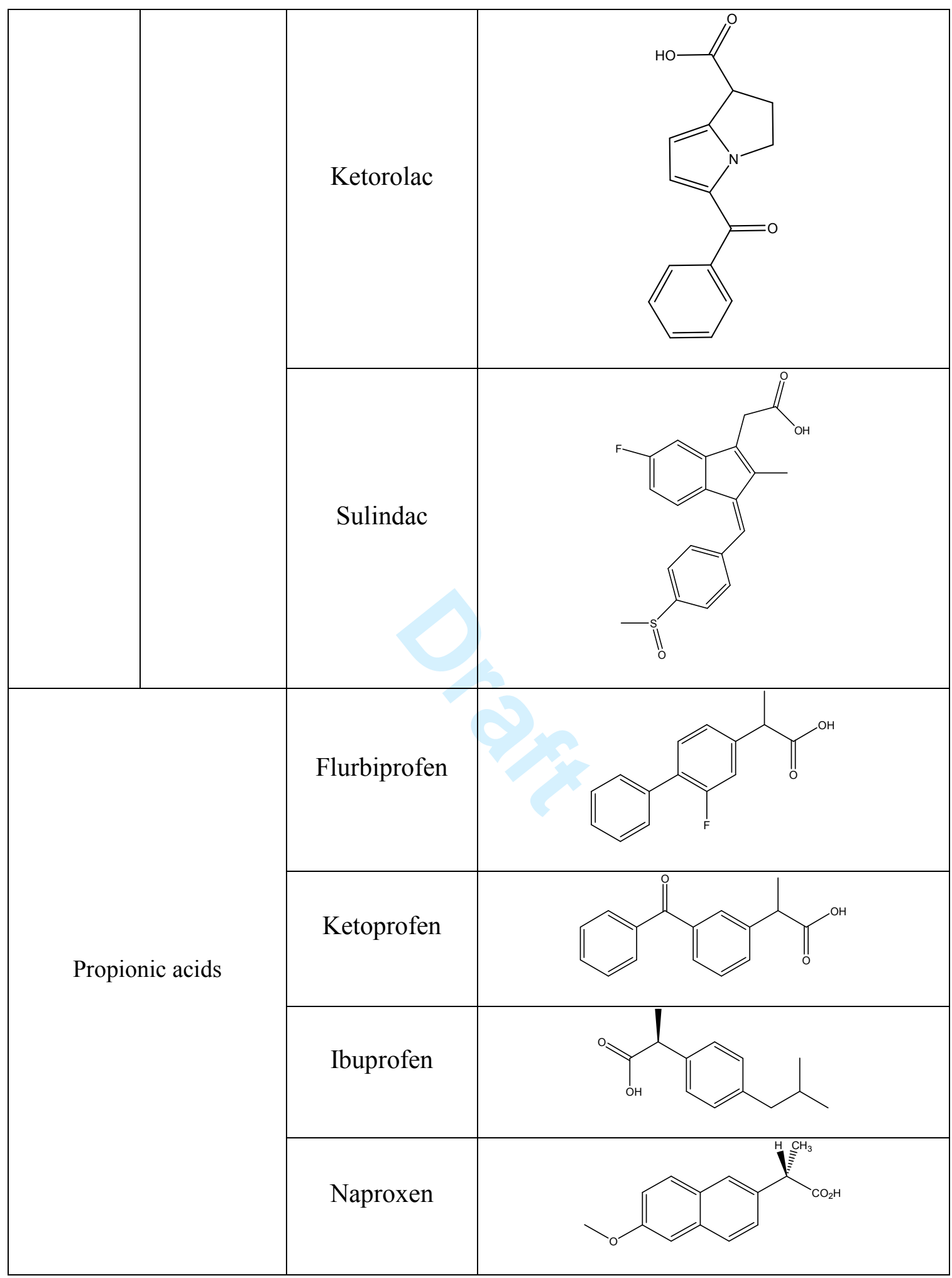




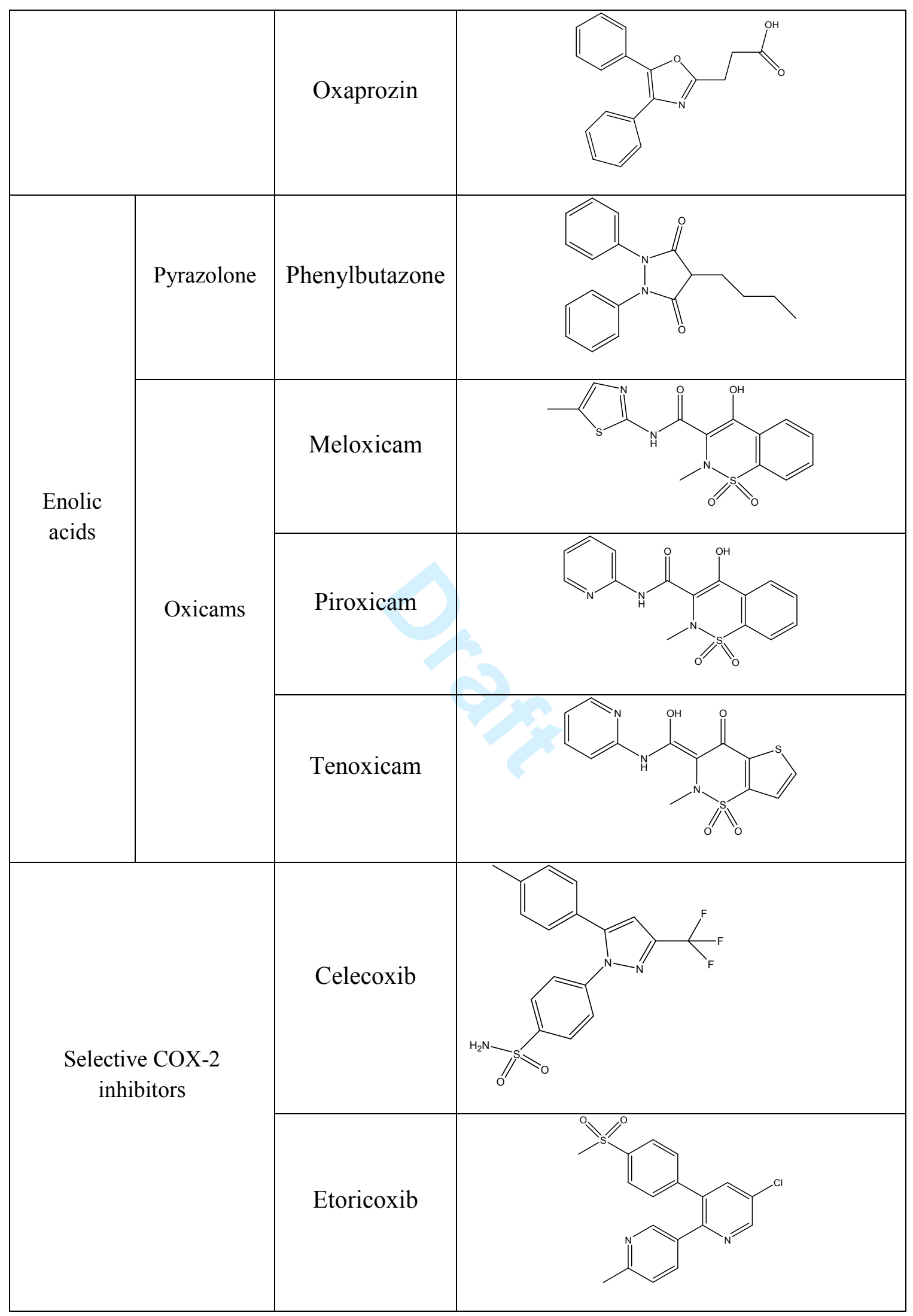




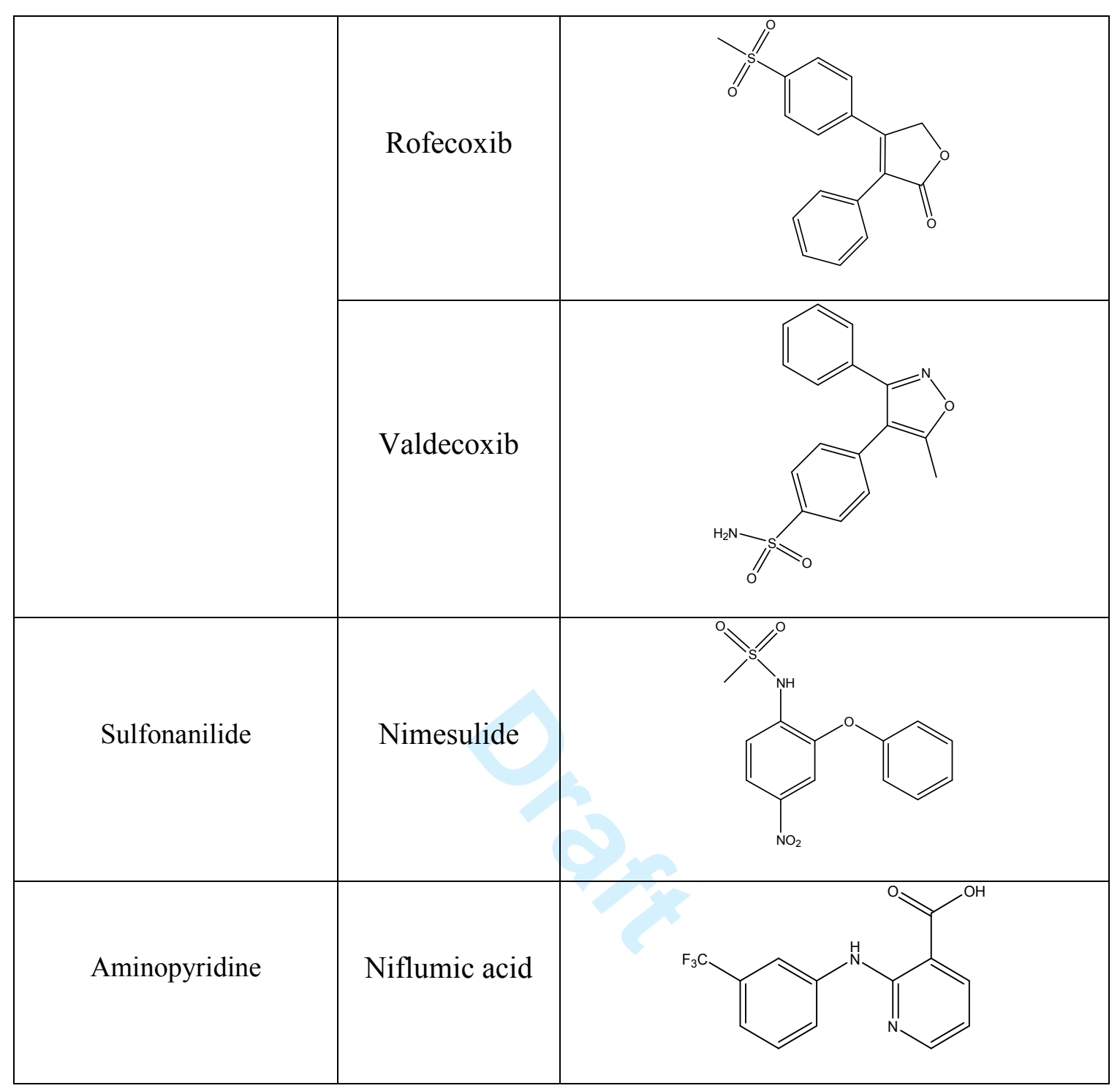


Table 2. Fibrillar aggregation properties of hIAPP incubated with different drug treatments at $100 \mu \mathrm{M}$, molar ratio 1:10. Data were obtained using a longer agitation. Standard deviation for each parameter was calculated.

\begin{tabular}{|c|c|c|c|c|}
\hline \multirow{2}{*}{$\begin{array}{c}\text { NSAIDs } \\
(100 \mu \mathrm{M})\end{array}$} & \multicolumn{4}{|c|}{ Fibril Formation $^{a}$} \\
\hline & $\underset{(\text { min) }}{\text { Lag time }^{b}}$ & $\begin{array}{c}T_{50}^{c} \\
(\min )\end{array}$ & $\begin{array}{c}\text { Intensity }^{\mathrm{d}} \\
(\%)\end{array}$ & Amyloidogenic \\
\hline Aceclofenac & $17.6 \pm 0.8$ & $40.8 \pm 0.3$ & $89.1 \pm 0.4$ & +++ \\
\hline Celecoxib & $13.1 \pm 0.7$ & $22.9 \pm 0.7$ & $74.0 \pm 0.4$ & ++ \\
\hline Deracoxib & $19.2 \pm 0.4$ & $39.2 \pm 0.5$ & $115.0 \pm 0.5$ & +++ \\
\hline Diclofenac & $20.7 \pm 0.8$ & $45.5 \pm 0.3$ & $55.9 \pm 0.3$ & ++ \\
\hline Etoricoxib & $27.6 \pm 0.4$ & $44.2 \pm 0.3$ & $118.8 \pm 0.7$ & +++ \\
\hline Flurbiprofen & $21.6 \pm 0.6$ & $41.5 \pm 0.2$ & $105.8 \pm 0.4$ & +++ \\
\hline Ibuprofen & $23.1 \pm 0.5$ & $40.1 \pm 0.2$ & $112.7 \pm 0.5$ & +++ \\
\hline Indomethacin & $19.1 \pm 0.9$ & $43.8 \pm 0.3$ & $75.9 \pm 0.7$ & ++ \\
\hline Ketoprofen & $21.9 \pm 0.6$ & $39.4 \pm 0.2$ & $106.1 \pm 0.3$ & +++ \\
\hline Ketorolac & $21.5 \pm 0.6$ & $37.9 \pm 0.2$ & $111.6 \pm 0.4$ & +++ \\
\hline Meloxicam & $16.3 \pm 0.7$ & $37.9 \pm 0.4$ & $32.8 \pm 0.2$ & + \\
\hline Naproxen & $20.0 \pm 0.6$ & $38.3 \pm 0.2$ & $106.7 \pm 0.5$ & +++ \\
\hline Niflumic acid & $17.6 \pm 0.3$ & $41.6 \pm 0.5$ & $45.9 \pm 0.4$ & ++ \\
\hline Nimesulide & $19.2 \pm 0.2$ & $37.0 \pm 0.3$ & $39.9 \pm 0.2$ & ++ \\
\hline Oxaprozin & $19.6 \pm 0.7$ & $37.9 \pm 0.2$ & $114.9 \pm 0.4$ & +++ \\
\hline Phenylbutazone & $21.4 \pm 0.4$ & $43.9 \pm 0.5$ & $62.8 \pm 0.7$ & ++ \\
\hline Piroxicam & $16.6 \pm 2.0$ & $38.4 \pm 0.3$ & $62.2 \pm 0.3$ & ++ \\
\hline Rofecoxib & $21.7 \pm 0.6$ & $40.1 \pm 0.2$ & $105.6 \pm 0.5$ & +++ \\
\hline Sulindac & $17.6 \pm 0.3$ & $39.9 \pm 0.4$ & $39.8 \pm 0.2$ & ++ \\
\hline Tenoxicam & $17.8 \pm 1.6$ & $38.1 \pm 0.2$ & $60.1 \pm 0.2$ & ++ \\
\hline Valdecoxib & $23.4 \pm 0.6$ & $39.9 \pm 0.2$ & $103.4 \pm 0.4$ & +++ \\
\hline Resveratrol & $7.2 \pm 1.0$ & $11.6 \pm 1.0$ & $10.7 \pm 0.4$ & - \\
\hline Silibinin & $17.6 \pm 0.2$ & $40.1 \pm 0.5$ & $52.1 \pm 0.5$ & ++ \\
\hline HFIP 1\% & $23.2 \pm 0.6$ & $39.9 \pm 0.2$ & $100.0 \pm 0.3$ & +++ \\
\hline
\end{tabular}

${ }^{\mathrm{a}}$ The concentration of hIAPP was $10 \mu \mathrm{M}$. 
b The lag time indicates the time during which no significant fibril formation occurs followed by a rapid growth phase.

${ }^{\mathrm{c}}$ The $\mathrm{T}_{50}$ represents the time to reach half of the maximum signal strength.

${ }^{\mathrm{d}}$ The fluorescence intensity of hIAPP alone was set as $100 \%$.

e The amyloidogenic parameter is a semi-quantitative analysis of ThT-fluorescence based amyloid formation: "+++" indicates samples with fluorescence intensity greater than 75 $\%$, "++" represents values between 40 and $75 \%$, "+" is set for values between 10 and 40 $\%$, and "-" underlines values lower than $10 \%$. 
Table 3. Fibrillar aggregation properties of hIAPP incubated with different effective drug treatments at 25 and $50 \mu \mathrm{M}$. Data were obtained using a longer agitation. Standard deviation for each parameter was calculated.

\begin{tabular}{|c|c|c|c|c|}
\hline \multirow{2}{*}{ NSAIDs } & \multicolumn{4}{|c|}{ Fibril Formation $^{a}$} \\
\hline & $\begin{array}{c}\text { Lag time }_{(\mathrm{min})}^{\mathrm{b}} \\
\end{array}$ & $\begin{array}{c}\mathbf{T}_{50}^{\mathrm{c}} \\
(\mathrm{min})\end{array}$ & $\begin{array}{c}\text { Intensity }^{\mathrm{d}} \\
(\%)\end{array}$ & Amyloidogenic ${ }^{\mathrm{e}}$ \\
\hline \multicolumn{5}{|c|}{$50 \mu \mathrm{M}$, molar ratio $1: 5$} \\
\hline Celecoxib & $19.1 \pm 0.5$ & $32.8 \pm 0.2$ & $131.0 \pm 0.8$ & +++ \\
\hline Diclofenac & $17.4 \pm 0.6$ & $31.4 \pm 0.2$ & $77.2 \pm 0.5$ & +++ \\
\hline Indomethacin & $13.8 \pm 0.6$ & $29.2 \pm 0.2$ & $107.6 \pm 0.7$ & +++ \\
\hline Meloxicam & $14.0 \pm 0.6$ & $29.1 \pm 0.2$ & $46.7 \pm 0.3$ & ++ \\
\hline Niflumic acid & $15.9 \pm 0.4$ & $30.6 \pm 0.3$ & $63.0 \pm 0.6$ & ++ \\
\hline Nimesulide & $15.7 \pm 0.6$ & $30.0 \pm 0.2$ & $54.7 \pm 0.3$ & ++ \\
\hline Phenylbutazone & $17.4 \pm 0.5$ & $31.6 \pm 0.2$ & $76.4 \pm 0.6$ & +++ \\
\hline Piroxicam & $13.8 \pm 0.4$ & $27.5 \pm 0.2$ & $93.6 \pm 0.7$ & +++ \\
\hline Sulindac & $15.5 \pm 0.4$ & $29.7 \pm 0.2$ & $58.3 \pm 0.5$ & ++ \\
\hline Tenoxicam & $15.3 \pm 0.5$ & $27.9 \pm 0.2$ & $94.3 \pm 0.5$ & +++ \\
\hline Resveratrol & $8.5 \pm 0.8$ & $21.8 \pm 0.6$ & $19.9 \pm 0.2$ & + \\
\hline Silibinin & $17.3 \pm 0.5$ & $30.8 \pm 0.1$ & $83.3 \pm 0.5$ & +++ \\
\hline \multicolumn{5}{|c|}{$25 \mu \mathrm{M}$, molar ratio $1: 2.5$} \\
\hline Diclofenac & $17.7 \pm 0.4$ & $31.3 \pm 0.3$ & $95.7 \pm 1.0$ & +++ \\
\hline Meloxicam & $15.3 \pm 0.3$ & $28.2 \pm 0.4$ & $64.0 \pm 0.7$ & ++ \\
\hline Niflumic acid & $15.9 \pm 0.3$ & $30.5 \pm 0.4$ & $77.1 \pm 1.1$ & +++ \\
\hline Nimesulide & $17.4 \pm 0.4$ & $30.0 \pm 0.2$ & $77.3 \pm 0.5$ & +++ \\
\hline Phenylbutazone & $17.3 \pm 0.4$ & $29.9 \pm 0.2$ & $91.9 \pm 0.7$ & +++ \\
\hline Sulindac & $17.0 \pm 0.3$ & $29.7 \pm 0.3$ & $74.1 \pm 0.8$ & +++ \\
\hline Resveratrol & $13.1 \pm 0.7$ & $27.6 \pm 0.2$ & $29.8 \pm 0.2$ & + \\
\hline Silibinin & $17.5 \pm 0.3$ & $30.1 \pm 0.3$ & $101.2 \pm 0.9$ & +++ \\
\hline HFIP 1\% & $17.3 \pm 0.8$ & $36.5 \pm 0.2$ & $100 \pm 1.0$ & +++ \\
\hline
\end{tabular}

\footnotetext{
${ }^{\mathrm{a}}$ The concentration of hIAPP was $10 \mu \mathrm{M}$.
} 
${ }^{\mathrm{b}}$ The lag time indicates the time during which no significant fibril formation occurs followed by a rapid growth phase.

${ }^{\mathrm{c}}$ The $\mathrm{T}_{50}$ represents the time to reach half of the maximum signal strength.

${ }^{\mathrm{d}}$ The fluorescence intensity of hIAPP alone was set as $100 \%$.

${ }^{\mathrm{e}}$ The amyloidogenic parameter is a semi-quantitative analysis of ThT-fluorescence based amyloid formation: "+++" indicates samples with fluorescence intensity greater than 75 $\%$, "++" represents values between 40 and $75 \%$, "+" is set for values between 10 and 40 $\%$, and "-" underlines values lower than $10 \%$. 
Table 4. Fibrillar aggregation properties of hIAPP incubated with different drug treatments at $100 \mu \mathrm{M}$, molar ratio 1:10. Data were obtained using a shorter agitation. Standard deviation for each parameter was calculated.

\begin{tabular}{|c|c|c|c|c|c|}
\hline \multirow{2}{*}{$\begin{array}{l}\text { NSAIDs } \\
(100 \mu \mathrm{M})\end{array}$} & \multicolumn{5}{|c|}{ Fibril Formation ${ }^{a}$} \\
\hline & $\begin{array}{c}\text { Lag time }^{\mathrm{b}} \\
\text { (min) }\end{array}$ & $\begin{array}{c}T_{50}^{c} \\
(\min )\end{array}$ & Slope & $\begin{array}{c}\text { Intensity }^{\mathrm{d}} \\
(\%)\end{array}$ & Amyloidogenic ${ }^{\mathrm{e}}$ \\
\hline Diclofenac & $69.3 \pm 1.6$ & $142.0 \pm 1.1$ & $35.4 \pm 1.2$ & $58.5 \pm 0.7$ & ++ \\
\hline Meloxicam & $38.9 \pm 1.4$ & $86.6 \pm 2.1$ & $35.1 \pm 1.8$ & $41.1 \pm 0.4$ & ++ \\
\hline Niflumic acid & $52.7 \pm 2.0$ & $101.4 \pm 1.0$ & $29.5 \pm 1.0$ & $56.2 \pm 0.4$ & ++ \\
\hline Nimesulide & $33.7 \pm 2.4$ & $73.6 \pm 1.9$ & $24.5 \pm 1.6$ & $59.0 \pm 0.5$ & ++ \\
\hline Phenylbutazone & $64.8 \pm 2.6$ & $141.1 \pm 0.4$ & $35.3 \pm 0.6$ & $72.8 \pm 0.4$ & ++ \\
\hline Piroxicam & $32.9 \pm 2.1$ & $70.6 \pm 1.7$ & $25.2 \pm 1.3$ & $75.5 \pm 0.5$ & +++ \\
\hline Sulindac & $27.6 \pm 2.3$ & $67.5 \pm 2.5$ & $27.8 \pm 1.8$ & $55.7 \pm 0.5$ & ++ \\
\hline Tenoxicam & $42.2 \pm 2.4$ & $85.7 \pm 1.6$ & $27.0 \pm 1.4$ & $71.1 \pm 0.6$ & ++ \\
\hline Resveratrol & $32.0 \pm 1.2$ & $51.5 \pm 1.8$ & $14.9 \pm 1.4$ & $8.8 \pm 0.1$ & - \\
\hline Silibinin & $33.5 \pm 2.1$ & $74.2 \pm 2.1$ & $26.8 \pm 1.7$ & $54.5 \pm 0.5$ & ++ \\
\hline HFIP $1 \%$ & $53.8 \pm 2.3$ & $105.3 \pm 0.7$ & $29.2 \pm 0.7$ & $101.2 \pm 0.5$ & +++ \\
\hline
\end{tabular}

${ }^{\mathrm{a}}$ The concentration of hIAPP was $10 \mu \mathrm{M}$.

${ }^{\mathrm{b}}$ The lag time indicates the time during which no significant fibril formation occurs followed by a rapid growth phase.

${ }^{\mathrm{c}}$ The $\mathrm{T}_{50}$ represents the time to reach half of the maximum signal strength.

${ }^{\mathrm{d}}$ The fluorescence intensity of hIAPP alone was set as $100 \%$.

${ }^{\mathrm{e}}$ The amyloidogenic parameter is a semi-quantitative analysis of ThT-fluorescence based amyloid formation: "+++" indicates samples with fluorescence intensity greater than 75 
$\%$, "++" represents values between 40 and $75 \%$, "+" is set for values between 10 and 40 $\%$, and "-" underlines values lower than $10 \%$. 